\title{
Minimum wage regulation in Switzerland: survey evidence for restaurants in the canton of Neuchâtel
}

\author{
Marius Berger ${ }^{1}$ and Bruno Lanz $2,3,4^{*}$
}

\begin{abstract}
This paper provides a first set of results on the impact of minimum wage regulation in Switzerland. We study the effects of an unexpected Supreme Court ruling mandating the Swiss canton of Neuchâtel to enforce a minimum hourly wage of around CHF 20 previously accepted via popular ballot. Given policy discontinuity at cantonal borders, we design a two-wave survey of restaurants to measure wages, employment, workers' characteristics, and prices and administer it in Neuchâtel as well as in geographically proximate districts of neighboring cantons. Our data covers preand post-enforcement outcomes for around 100 restaurants, with information for more than 800 employees distributed over two-survey waves. Our data suggest that the proportion of workers paid below minimum wage went down from 19\% to 5\% after the introduction of the policy. This decline is compensated by a significant increase of the workforce paid just above minimum wage, and our results suggest that restaurants did not use employment as a margin of adjustment. We also find evidence that the policy affected the distribution of hourly wages up to CHF 6 above the minimum wage, with some workers initially paid above minimum wage experiencing a wage increase.
\end{abstract}

Keywords: Minimum wage regulation, Wage distribution, Workforce composition, Low-wage jobs, Restaurant industry

JEL Codes: J21; J23; J38; C83; R23

\section{Introduction}

Minimum wage regulation is controversial. On the one hand, by increasing wage income for workers in the lower tail of the wage distribution, minimum wage regulation can achieve distributional objectives and reduce reliance of workers on transfer payments by the state (Lee and Saez 2012). On the other hand, regulation increases the cost of labor for firms, which may imply that some workers loose their jobs (see Allegretto et al. 2017; Neumark and Wascher 2017 for a recent discussion of empirical results). Achieving higher wages for some workers may thus come at the risk of unemployment for other workers, for example through changes in workforce composition

*Correspondence: bruno.lanz@unine.ch

University of Neuchâtel, Neuchâtel, Switzerland

Full list of author information is available at the end of the article and labor-labor substitution (see, e.g., Giuliano 2013; Lang and Kahn 1998).

In Switzerland, the introduction of minimum wage regulation regularly comes up in the political agenda both in individual cantons and at the federal level ${ }^{1}$. Given peculiarities associated with the Swiss context, such as relatively low unemployment and a history of self-regulation including collective labor agreements (CLA) negotiated between employers and employees, evidence on how firms adjust to minimum wage regulation in Switzerland is important. In line with this, the main contribution of this paper is to provide a first set of results on the effects

\footnotetext{
${ }^{1}$ Examples include the canton of Geneva, where a cantonal initiative was rejected in 2011, and the canton of Ticino, where citizens voted in favor of a minimum wage in 2015 (see Di Stefano 2018; Della Pietra 2018). At the federal level, a popular initiative for a minimum wage of CHF 22 per hour was rejected with 73.6 percent of the votes in 2014 .
} 
of minimum wage regulation in Switzerland. More specifically, we study the introduction of a minimum wage of CHF 19.78 per hour accepted via popular ballot in Neuchâtel, making it the first Swiss canton to enforce such a regulation.

Our data are derived from an original survey targeting managers in the restaurant industry, and this for three main reasons. First, while data linking firms and workers is necessary to quantify the effects of minimum wage regulation, the availability of spatially disaggregate firm-level data matched to worker information is limited, mainly because of anonymity concerns. Instead, we build on the questionnaire by Card and Krueger (1994) measuring important restaurant-level outcomes such as employment and prices and enrich it to obtain detailed worker-level information on wages, work-time, and worker characteristics for all restaurant employees. The resulting firm-worker dataset allows us to study withinrestaurant labor-labor substitution and document how the wage distribution in our sample responds to minimum wage regulation. Second, industry-level data mitigates concerns that inter-industry growth differentials unrelated to the regulation could confound the estimation of regulatory impacts (Dube et al. 2007). Third, an official report by the Council of State of Neuchâtel (2013) suggests that the restaurant industry in Neuchâtel is among the sectors that are most exposed to the regulation, with around 15\% of employment earning less than CHF 20 per hour. In addition, the average number of employees per firm in this sector is relatively low (3.33 full-time equivalent, FTE, per restaurant in Neuchâtel in 2016), and the largest employers' association in this sector (GastroSuisse 2018) reports that on average restaurants in Switzerland spend more than half of their revenues on the workforce. In turn, small changes in the payroll may affect profitability in this sector ${ }^{2}$.

In an attempt to quantify the impact of regulation on restaurants in Neuchâtel, we administer our questionnaire both before and after regulation is enforced. As we detail below, minimum wage regulation was initially accepted during a cantonal ballot in 2011, although a number of appeals were raised to the Federal Supreme Court. After years of deliberation, on August 4 2017, the Supreme Court unexpectedly announced that all the appeals had been rejected. In turn, on October 25, 2017, the cantonal government of Neuchâtel officially announced the introduction of a minimum wage set at CHF 19.78, with compliance control starting in January 2018. The first wave of our survey, which took place in September 2017, is therefore in-between the announcement by the Supreme Court and the enforcement by the cantonal government.

\footnotetext{
${ }^{2}$ We also note that the restaurant sector is widely studied in the minimum wage literature (see Neumark and Wascher 2008 for a review). Our work can be seen as a case study application in the context of Switzerland.
}

Because some firms may have undertaken anticipated adjustments, the questionnaire explicitly focuses on the situation in the summer season (July and August) $2017^{3}$. In the second survey wave after enforcement (April 2018), we refer to the situation in both spring 2018 and summer 2018 to account for potential seasonal variability. We note, however, that spring and summer outcomes for 2018 are elicited simultaneously, so that projections for summer 2018 should be interpreted as expectations by restaurants managers.

One key challenge to quantify minimum wage impacts is to generate counterfactual evidence for outcomes in jurisdictions under minimum wage regulation (Neumark et al. 2014). In our context, this requires some evidence about how wages, employment, workforce composition, and prices would have changed in restaurants of Neuchâtel in the absence of minimum wage regulation. Following a large literature on the topic (see, e.g., Allegretto et al. 2011; AAronson et al. 2018; Addison et al. 2009; Card and Krueger 1994; Dube et al. 2010), we exploit policy discontinuity at jurisdictional borders and also administer our two-wave survey in restaurants located in geographically proximate districts of neighboring cantons not subject to minimum wage regulation. Restaurants in these control districts can be expected to face labor and product market conditions that are comparable to those prevailing in the canton of Neuchâtel, except of course from the introduction of minimum wage regulation (see Allegretto et al. 2017 for empirical evidence supporting this approach) $)^{4}$.

In this setting, we employ a difference-in-differences (DD) approach that exploits the evolution of wages and employment (both headcount and FTE) in control districts to inform counterfactual wages and employment for restaurants in the canton of Neuchâtel. Similarly, we investigate the comparative evolution of workforce composition and prices in Neuchâtel and in control districts. Aside from restaurant-level impacts, we further exploit our worker-level data to document the evolution of the wage distribution in our sample. We follow the procedure of Harasztosi and Lindner (2019) and Cengiz et al. (2019) and use observed changes in control districts to construct a counterfactual post-treatment wage distribution in Neuchâtel (see also Jardim et al. 2017 for a related approach). By comparing actual and counterfactual posttreatment wage distributions, we obtain non-parametric evidence on how regulation affects low-wage employment

\footnotetext{
${ }^{3}$ As we discuss in Section 5, if some restaurants anticipated enforcement of minimum wage regulation our results would tend to underestimate the true impacts of the regulation. See for example Aaronson (2001) and Renkin et al. (2017) on this issue.

${ }^{4}$ Since we only administered our survey once before minimum wage regulation is enforced, we cannot use our data to document that restaurants in Neuchâtel and in control districts follow the same trend over time. Nevertheless, below we provide some evidence that aggregate unemployment trends are relatively similar in Neuchâtel and in control districts.
} 
in our sample. In addition, this approach allows us to document potential "ripple" effects across wage bins, whereby workers with pre-treatment wages above the minimum also benefit from the regulation (see, e.g., Cengiz et al. 2019; Neumark et al. 2004).

Our results can be summarized as follows. In the first wave of the survey, 126 restaurant managers completed the questionnaire (60\% participation rate). Among these, 113 also participated in the second wave (60 in the canton of Neuchâtel), providing detailed information for more than 800 employees distributed over both survey waves ${ }^{5}$. Data from the first wave of the survey indicate that $19 \%$ of restaurant employees in Neuchâtel have pre-enforcement wages below the regulatory minimum. In restaurants paying wages below CHF 19.78 (46.1\% of restaurants in Neuchâtel), about $50 \%$ of the workforce is entitled to an increase in wages, and the average increase in the total wage bill to comply with the regulation is $3.81 \%$.

Post-enforcement, the second wave of the survey reveals that the share of employees paid below CHF 19.78 decreases to around $5 \%^{6}$. Controlling for changes observed in control regions, a set of DD regressions confirms a significant increase in the lowest wages paid by restaurants, whereas average wages are not affected by the policy. Our results further suggest that minimum wage regulation in Neuchâtel did not reduce restaurant-level employment, and data on the wage distribution for summer 2018 even suggest a small increase of employment, whereby the decline in the number of employees in wage bins below the regulatory minimum $(-12.4 \%)$ is more than compensated by an increase in the wage bin just above $(+15.2 \%)$. Regression results, however, suggest that this increase of employment is not statistically significantly different from zero.

These results are broadly in line with a large empirical literature finding no or modest employment effects associated with minimum wage regulation. For example, a number of papers study the impact of the 1992 increase in minimum wage in New Jersey, using outcomes in neighboring Pennsylvania to construct local comparisons, with Card and Krueger (2000) reporting no disemployment effects and Neumark and Wascher (2000) finding small negative employment effects. See Cengiz et al. (2019) for a recent and comprehensive investigation across the US

\footnotetext{
${ }^{5}$ Throughout the paper, we exclude data for restaurant managers and members of their family who work in the restaurants. First, these employees are often part of restaurant ownership, and as such they are not subject to minimum wage regulation. In fact, these wages are expected to mainly reflect profitability of the activity. Second, the non-response rate for managers' wages is above $70 \%$.

${ }^{6}$ This result is in line with anecdotal evidence on non-compliance in the canton of Neuchâtel (see Giroud 2018). However, we may over-estimate compliance given possible measurement error and strategic misreporting by restaurant managers. We come back to non-response and potential selection effects below.
}

states, reporting no evidence of disemployment in nontradable sectors. Studies on minimum wage regulation in Europe report similar results, with estimates either statistically insignificant or close to zero. For example, Metcalf (2008) and Leonard et al. (2014) report that the 1999 minimum wage regulation in the UK had no significant impact on employment, while Machin et al. (2003) provides evidence that the policy negatively affected specific sectors (such as the residential care industry). More recently, an empirical analysis of the 2015 minimum wage regulation in Germany also found no negative impacts on employment (Ahlfeldt et al. 2018).

Changes in the distribution of wages further reveal the presence of ripple effects for wage bins up to CHF 6 above the minimum wage. Specifically, we find evidence that some workers initially paid above minimum wage also experience a wage increase after the introduction of the regulation. As a point of comparison, using data from the USA, Cengiz et al. (2019) similarly report the presence of ripple effects up to $\$ 3$ above the minimum wage. We also find suggestive evidence that the proportion of nonqualified workers increases following the introduction of a minimum wage. This finding is related to Giuliano (2013) who shows that an increase in the relative wages of teenagers following an increase of minimum wage in the USA led to higher employment for this group of worker and is consistent with imperfectly competitive models of the labor market. We note, however, that our results in this dimension are only marginally statistically significant, and more evidence on how minimum wage regulation affected the demand for non-qualified workers in the Swiss context is needed. Lastly, our data provides little evidence that restaurants increased prices (see also Lemos 2008 for a survey), although we emphasize that further work is needed to document longer-term impacts, including profitability.

The remaining of the paper is structured as follows. In Section 2, we briefly summarize the institutional background that led to the introduction of minimum wage regulation in the canton of Neuchâtel. Section 3 describes the details of our empirical strategy. In Section 4, we provide empirical results derived from our survey. Section 5 discusses the interpretation of our results and a number of potential caveats. Section 6 briefly concludes.

\section{Institutional background and timing of the regulation}

In November 2011, 54.64\% of voters in the canton of Neuchâtel supported the introduction of a minimum wage in the constitution of the canton ${ }^{7}$. Following the ballot, cantonal authorities established an extra-parliamentary

\footnotetext{
${ }^{7}$ Any changes to the constitution of the canton of Neuchâtel is automatically submitted to a popular vote. In the present case, the constitutional amendment stems from the cantonal parliament.
} 
commission to draft the constitutional amendment. The proposal, finalized in November 2013, targeted a real wage rate of CHF 20 (approx. \$20) per hour for all employees in the canton, an amount selected to reduce the need for low-wage workers to seek welfare benefits in order to supplement their work income (see Council of State of Neuchâtel 2013).

Parliamentary discussions on the application of the amendment went on until May 2014, when the parliament accepted a project based on the original CHF 20 per hour wage rate, but with some exemptions (such as independent workers, apprentices, and those in the agricultural sector). In July 2014, however, a number of appeals were brought to the Federal Supreme Court of Switzerland, and these led to the suspension of the constitutional amendment. One appeal, which involved the main organization representing restaurant owners in Neuchâtel (GastroNeuchâtel), claimed that such legislation was contrary to the constitutional principle of economic freedom (see Federal Court 2017). While the Federal Court regularly invalidates ballot procedures if a constitutional right is violated, after an extended period of deliberation, the court rejected all the appeals and announced its decision on August 4, 2017.

Given the unexpected nature of the court ruling and its unanticipated timing, a number of important aspects of the regulation remained unknown at the time of the announcement. This includes the effective minimum wage rate after adjustment for inflation. Therefore, on October 25, 2017, cantonal authorities officially communicated about the implementation of the regulation, with a minimum wage rate adjusted to CHF 19.78 to match price indexation, and announced that the beginning compliance controls would start in January 2018 (Bysaeth 2018) to allow for a short period of adaptation. This made Neuchâtel the first Swiss canton to introduce a minimum wage in its legislation.

Estimates produced during parliamentary discussions suggest that minimum wage regulation would affect 2700 FTE workers across all sectors in the canton of Neuchâtel and would cost employers around CHF 9 millions, corresponding to a $0.21 \%$ increase in the total wage bill of the private sector. Based on this, the report by the Council of State of Neuchatel (2013) argues that the minimum wage regulation is not expected to have negative employment impacts. Importantly, restaurants in all Swiss cantons are subject to a CLA between employers and employees, which specifies a minimum hourly wage of CHF 18.98 in small restaurants, CHF 19.58 in seasonal restaurants, and CHF 20.33 in others (ordinary) restaurants $^{8}$. One implication is that, in principle, only

\footnotetext{
${ }^{8}$ These figures are from the CLA settled in January 2017 (Kontrollstelle L-GAV 2017). Small restaurants are those with less than four FTE employees (excluding the manager, but including the manager's family members), while
}

small and seasonal restaurants are expected to be affected by the regulation, and even for those the magnitude of the wage increase is relatively small, which can explain the conclusions reported in Council of State of Neuchâtel (2013). As we discuss below, however, while all firms have to comply with a CLA negotiated in their sector of activity, exemptions are possible and compliance controls are not systematic.

\section{Empirical strategy}

This section describes our empirical strategy. First, we present the questionnaire and its administration to restaurant managers in the canton of Neuchâtel and in control districts. Second, we introduce a set of econometric tools used to quantify the impact of minimum wage regulation.

\subsection{Survey instrument}

The main objective of the survey is to obtain detailed firmworkers data covering pre- and post-regulation for a sample of restaurants in the canton of Neuchâtel as well as in neighboring areas where no minimum wage regulation is introduced. We follow the approach of Card and Krueger (1994) and design a two-wave survey administered before and after minimum wage regulation is enforced in January 2018.

The questionnaire for the first wave, administered in September 2017, closely follows the structure used by Card and Krueger (1994) $)^{9}$. We start by eliciting information about opening times and the number of meals served and then move to questions about employment and working contracts in the restaurant. To mitigate concerns associated with possible anticipation effects following the announcement of the Supreme Court and avoid idiosyncrasies associated with the end of peak season (e.g., for seasonal restaurants), the questionnaire explicitly refers to the situation prevailing during the summer season (July and August 2017).

A notable difference with Card and Krueger (1994) is a set of questions focusing on worker-level information for all employees of the restaurant, including hourly wages, working hours, workers' qualifications, occupation within the restaurant, and family ties with the manager. These additional questions serve two objectives. First, workerlevel characteristics allow us to obtain a unique set of data linking firms and employees, capturing differences in skills and wages within restaurants. Second, worker-level data can be used to study changes in the distribution of wages in the sample and complement a restaurant-level approach used in Card and Krueger (1994).

seasonal restaurants are those with one or several peak seasons (defined as a period of 3 to 9 months in which average monthly turnover is at least 35\% higher than in other months).

${ }^{9}$ The questionnaire for both waves of the survey is provided in Additional file 1 for reference. 


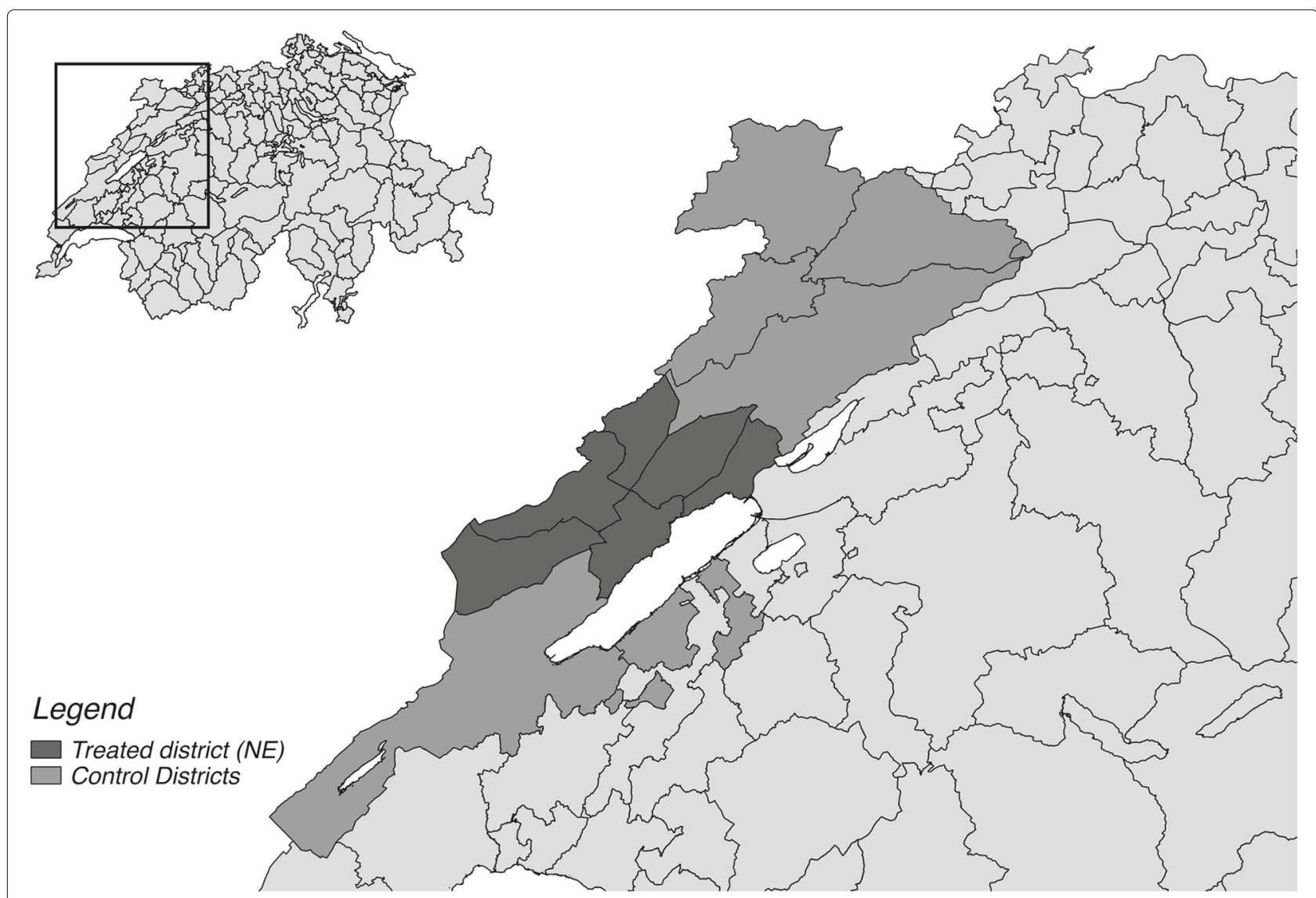

Fig. 1 Geographical location of treated and control districts in Switzerland

Lastly, the questionnaire measures prices for standard products that can be compared across restaurants, and for restaurants in the canton of Neuchâtel, we also ask a set of questions that focus on the introduction of minimum wage regulation. This provides evidence on expectations about upcoming regulation by restaurant managers, including impacts on operation costs, profits, and overall management.

Restaurants invited to take part in the first wave of the survey are selected on the basis of their geographic location. For those in the canton of Neuchâtel, we construct a list of restaurants by merging all entries from the commercial registry and those from the official online directory. For the control group, we follow Dube et al. (2010) and Allegretto et al. (2011) and focus on restaurants located in comparable geographical areas of contiguous cantons, namely french-speaking parts of Bern and Fribourg, the canton of Jura, as well as the district "Jura-Nord vaudois" in Vaud ${ }^{10}$. The geographical location of control districts is illustrated in Fig. 1. Based on this, we proceed by constructing a list of restaurants in control areas using

\footnotetext{
${ }^{10}$ Specifically, the control districts are Jura bernois, La Broye, Jura-Nord vaudois, and all districts in the canton of Jura.
}

again the commercial registry and official online directory.

To further motivate the choice of regions included in the survey, Table 1 reports a set of structural characteristics for each region together with corresponding figures for Switzerland. This data shows that age and gender are similar across study regions and Switzerland, whereas the share of foreigners and agricultural surface area are still very similar in control and treated districts but differ from figures reported for Switzerland as a whole. Furthermore, regional results for two federal-level popular initiatives, namely the 2014 ballot on minimum wage and the 2016 ballot for an unconditional basic income, also suggest that the approval rate are similar for the two regions considered, although significantly higher than federal-level results.

In order to document labor market opportunities for treated and control districts, Fig. 2 reports data from SECO (2018) on unemployment trends. Specifically, panel a shows the aggregate number of unemployed workers in treated vs. control districts and panel b provides the same but for the restaurant sector alone. The data suggest that the two regions are comparable in terms of the 
Table 1 Structural characteristics of regions included in the survey

\begin{tabular}{llll}
\hline & Control districts & $\begin{array}{l}\text { Treated } \\
\text { districts (NE) }\end{array}$ & Switzerland \\
\hline $\begin{array}{l}\text { Average age } \\
\text { (years) }\end{array}$ & 41.27 & 41.50 & 41.70 \\
$\begin{array}{l}\text { Share of } \\
\text { female (\%) }\end{array}$ & 0.50 & 0.51 & 0.50 \\
$\begin{array}{l}\text { Share of } \\
\text { foreigners } \\
\text { (\%) }\end{array}$ & 0.20 & 0.20 & 0.25 \\
$\begin{array}{l}\text { Share of } \\
\text { agricultural } \\
\text { area (\%) }\end{array}$ & 0.48 & 0.45 & \\
$\begin{array}{l}\text { Minimum } \\
\text { wage } \\
\text { initiative (yes } \\
\text { \%) }\end{array}$ & 0.31 & 0.32 & \\
$\begin{array}{l}\text { Basic } \\
\text { revenue } \\
\text { initiative (yes } \\
\%)\end{array}$ & 0.29 & 0.24 & \\
\hline
\end{tabular}

Notes: This table reports district-level data across treated and control regions.

Treated districts include all districts in the canton of Neuchâtel, while districts in the control region are Jura bernois, La Broye, Jura-Nord vaudois, and all districts in the canton of Jura. Data for Switzerland as a whole is reported for comparison purpose. Source: Swiss Federal Office for Statistics, 2017

scale and trend of total registered unemployed workers and support the view that both regions trend together in terms of employment opportunities ${ }^{11}$. We emphasize, however, that this evidence is only indirectly informative about common trend in the outcomes considered in our analysis. Specifically, we would need at least one additional survey wave before enforcement of the minimum wage regulation in order to document a common trend among restaurants in our sample.

For each region, we randomly select restaurants and contact these via the registered phone number. Managers are invited to participate in an independent academic study on economic opportunities in the restaurant sector, and we offer a CHF 30 financial compensation for the time dedicated to our survey. Table 2 summarizes survey administration and response rates across survey areas. We contacted a total of 210 restaurant managers, equally distributed across treatment and control areas ${ }^{12}$. Among these, 126 (60\%) completed the first wave of the survey. While participation rate in the first wave varies slightly across cantons in the control areas (lowest for Bern with around 35\% participation rate, highest for Jura

\footnotetext{
${ }^{11}$ We note that trends for the restaurant sector (Fig. 2, b) display more volatility than aggregate figures, with some sign of convergence already before 2018. However, taking the difference measured in the year 2014 as a baseline, the differential change between Neuchâtel and control districts is not statistically significantly different from zero.

${ }^{12}$ This corresponds to around $10 \%$ of entries included in our list of restaurants. Note that for the canton Vaud, we focus on a single district, so that the number of contacts for this canton is comparatively small.
}

with almost $85 \%$ ), it is very similar across treatment and control groups, with $60.95 \%$ in the canton of Neuchâtel and $59.05 \%$ in control areas.

The second wave of the survey, administered in April 2018, focuses on post-treatment outcomes for the set of restaurants that participated in the first wave. We keep the same structure for the questionnaire, but ask managers to report employment and wage data for both spring 2018 and summer 2018 in order to account for possible seasonality effects ${ }^{13}$. We also shorten the questionnaire by dropping redundant questions and increase financial compensation offered to participants to CHF 50 in an attempt to minimize attrition.

As shown in Table 2, the second wave includes data for 113 restaurant, and the implied attrition rate of about $10 \%$ is broadly line with Card and Krueger (1994). In the canton of Neuchâtel, one restaurant ceased operations, and three managers refused to participate, while in control districts, one more restaurant closed down, and eight declined to participate.

\subsection{Econometric estimation}

We now detail how we exploit the data derived from our survey. We begin with a restaurant-level DD approach quantifying average impacts of minimum wage regulation on restaurants in Neuchâtel. We then turn to a distribution-based approach, which we use to investigate employment impacts across the distribution of wages in our sample.

\subsubsection{Restaurant-level outcomes}

Denote outcome $j$ for restaurant $i$ at time $t$ as $Y_{j i t}$. The set of outcomes $j$ includes the share of sub-minimum wage workers, FTE employment, or the price of a glass of soda for example. The set of time periods is summer 2017, spring 2018, and summer 2018, where the last time period represents expectations by restaurant managers as noted previously. We implement regression-based DD estimation as a set of fixed-effect OLS regressions:

$$
\begin{aligned}
Y_{j i t} & =\beta_{j}^{\text {spring }} \cdot D D_{i t}^{\text {spring }}+\beta_{j}^{\text {summer }} \cdot D D_{i t}^{\text {summer }} \\
& +\gamma_{j} X_{i t}+\eta_{i}+\delta_{t}+\epsilon_{j i t},
\end{aligned}
$$

where $D D_{i t}^{\text {spring }}$ and $D D_{i t}^{\text {summer }}$ are indicator variables equal to one if restaurant $i$ is in the canton of Neuchatel and $t$ is spring 2018 or summer 2018, respectively, zero otherwise. In these regressions, we control for restaurant-specific fixed effects $\left(\eta_{i}\right)$ and industry-wide period-specific fixed effects $\left(\delta_{t}\right)$, so that the parameters $\beta_{j}^{\text {spring }}$ and $\beta_{j}^{\text {summer }}$ quantify how restaurants in Neuchâtel deviate from the trend for outcome $j$ observed in control districts in

\footnotetext{
$\overline{{ }^{13} \text { We emphasize that data referring }}$ to summer 2018 mainly captures expectations by restaurants managers, and in the analysis, we treat these data separately from those referring to spring 2018.
} 


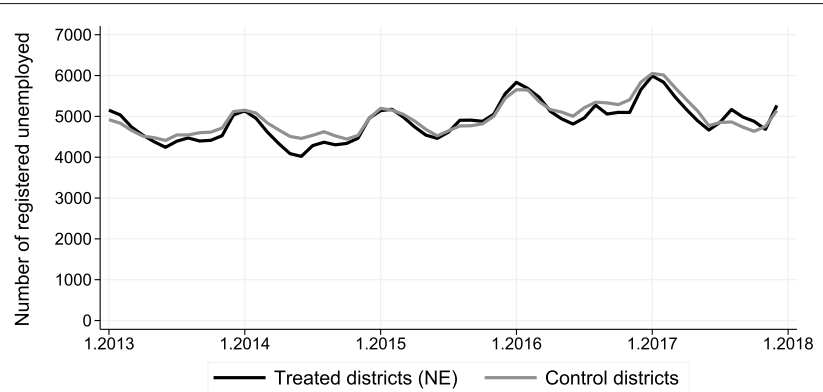

(a) All sectors

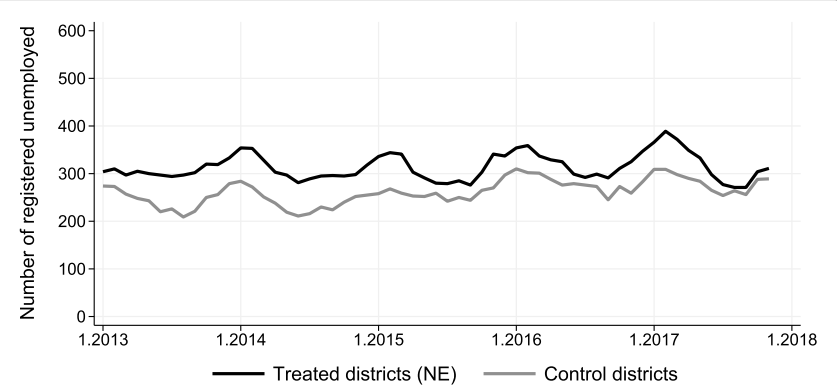

(b) Restaurant sector (NOGA 56)

Fig. 2 Pre-treatment trends in regional unemployment (data: SECO 2018)

spring or summer 2018, respectively. The regressions also include potential time-varying confounders $X_{i t}$ which can plausibly be assumed not to be affected by the regulation. In particular, we check for the sensitivity of our results to the inclusion of two measures of demand-side shocks, namely the average number of meal served during weekdays and those served over the weekend. Finally, $\epsilon_{j i t}$ is an error term.

\subsubsection{Distribution-based approach}

As a complement to DD regressions, the distributionbased approach allows us to document changes in employment for low-wage jobs in our sample, as illustrated in Fig. 3. Starting from an arbitrary pre-treatment wage distribution, introducing minimum wage $W_{\min }$ implies that employees with wages below the regulatory limit can either get a wage increase or lose their job. ${ }^{14}$ In the post-treatment distribution, minimum wage regulation generates excess mass (or bunching) just above $W_{\min }$, which can be interpreted as a non-parametric indicator that jobs below $W_{\min }$ are preserved. In turn, this may induce ripple effects among employees with wages between $W_{\min }$ and $\bar{W}$.

For observations in the canton of Neuchâtel, differences between pre- and post-treatment wage distributions may reflect the influence of other factors changing with time and thus fail to identify regulatory impacts. Following Harasztosi and Lindner (2019) and Cengiz et al. (2019), we use the evolution of the wage distribution in control districts to inform a post-treatment counterfactual wage distribution for the canton of Neuchâtel. ${ }^{15}$ We start by discretizing the wage distribution into $K$ intervals, where $k=$ 0 represents the wage bin just above the minimum wage.

\footnotetext{
${ }^{14}$ In reality, some employment below $W_{\min }$ is likely to be observed after enforcement (Cengiz et al. 2019).

${ }^{15}$ Note that Cengiz et al. (2019) pool data from multiple changes in minimum wage regulation and apply their estimator in the context of a panel regression. In our study, we only have one regulatory shock and focus on non-parametric specifications, with the drawback that standard-errors for the ensuing estimates cannot be calculated.
}

For each $k$ bin, we then compute the count of employees in Neuchâtel and control areas normalized by pre-treatment total employment in the respective regions:

$$
e_{r t}^{k}=\frac{E_{r t}^{k}}{E_{r, p r e}},
$$

where $E_{r t}^{k}$ is the number of employees in bin $k$, region $r=$ $\{N E$, CTRL $\}$, and time $t=\{$ pre, post $\}$, while $E_{r, p r e}$ denotes total pre-treatment employment in region $r$.

Next, we construct a post-treatment counterfactual

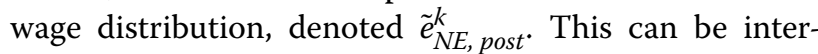
preted as the wage distribution that would have been observed in Neuchâtel if no minimum wage regulation had been enforced, and the evolution of the distribution would have been the same as in neighboring areas. Formally, this is given by:

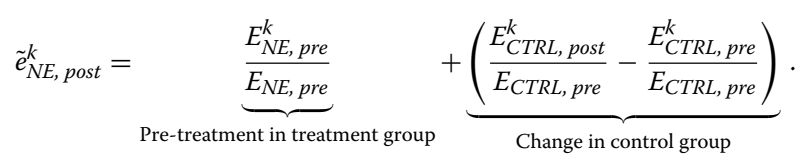

Finally, the change in employment associated with minimum wage regulation in each wage bin $k$, denoted $\rho^{k}$, is defined as the difference between actual and counterfactual post-treatment wage distributions:

$$
\begin{aligned}
& \rho^{k}=e_{N E, \text { post }}^{k}-\tilde{e}_{N E, \text { post }}^{k}=\underbrace{\frac{E_{N E, \text { post }}^{k}}{E_{N E, \text { pre }}}-\frac{E_{N E, \text { pre }}^{k}}{E_{N E, \text { pre }}}}_{\text {Change in treatment group }} \\
& -\underbrace{\left(\frac{E_{\text {CTRL, post }}^{k}}{E_{\text {CTRL, pre }}}-\frac{E_{\text {CTRL, pre }}^{k}}{E_{C T R L, p r e}}\right)}_{\text {Change in control group }} \text {. }
\end{aligned}
$$

It follows that total employment impacts are given by the cumulative changes across wage bins up to $\bar{W}$. 
Table 2 Data collection summary across survey waves and sampling regions

\begin{tabular}{|c|c|c|c|c|c|c|c|}
\hline & \multirow[t]{2}{*}{ Total } & \multicolumn{5}{|c|}{ Control group } & \multirow{2}{*}{$\begin{array}{l}\text { Treatment group } \\
\text { Neuchâtel }\end{array}$} \\
\hline & & All & Jura & Fribourg & Vaud & Bern & \\
\hline \multicolumn{8}{|c|}{ First wave (September 2017) } \\
\hline Manager contact & 210 & 105 & 33 & 28 & 12 & 32 & 105 \\
\hline Participants & 126 & 62 & 28 & 18 & 5 & 11 & 64 \\
\hline Response rate (\%) & 60.00 & 59.05 & 84.85 & 64.29 & 41.67 & 34.38 & 60.95 \\
\hline \multicolumn{8}{|l|}{ Second wave (April 2018) } \\
\hline Permanently closed & 2 & 1 & 1 & 0 & 0 & 0 & 1 \\
\hline Manager contact & 124 & 61 & 27 & 18 & 5 & 11 & 63 \\
\hline Participants & 113 & 53 & 25 & 15 & 4 & 9 & 60 \\
\hline Response rate (\%) & 91.29 & 86.89 & 92.59 & 83.33 & 80.00 & 81.82 & 95.24 \\
\hline Attrition (\%) & 10.32 & 14.52 & 10.71 & 16.67 & 20.00 & 18.18 & 6.25 \\
\hline
\end{tabular}

Notes: This table summarizes participation in the phone-based survey across survey waves and sampling areas. Restaurants in the control group are in the canton of Jura, and the districts Jura bernois, La Broye, and Jura-Nord vaudois

\section{Results}

This section presents the main empirical results. We first provide descriptive evidence about the pre-treatment composition of our sample and discuss sample representativeness and missing observations. We also document the bite of minimum wage regulation for restaurants in Neuchâtel. Second, we quantify the impact of minimum wage regulation by comparing the evolution of outcomes across control and treated regions. We focus on four sets of outcomes: (i) wages, (ii) employment, (iii) workforce composition, and (iv) prices.

\subsection{Descriptive evidence from the survey}

In Table 3, we compare pre-treatment averages across subsamples focusing on employment and wages, workforce composition, prices, and restaurant capacity. As previously mentioned, employment and wage data exclude managers and members of their family, mainly because of a non-response rate for wages in excess of $70 \%$, but also because these employees are potentially part of restaurant ownership and therefore not subject to the regulation. One implication is that six restaurants have no employees and thus drop out of the analysis, yielding a sample size of 107 restaurants ${ }^{16}$. Furthermore, nine restaurants do not report wages, 15 restaurants do not provide working hours for all employees, and data on the number of meals served and the price of daily specials is also missing for a small number of restaurants. This gives an estimation sample of 94 restaurants for employment and wage data and 88 restaurants for FTE employment ${ }^{17}$.

\footnotetext{
${ }^{16}$ Note that wages of apprentices are also not affected by minimum wage regulation. In our data, five employees are identified as apprentices, and we therefore exclude these from estimation of wage impacts. However, they are part of employment counts and other measures of workforce composition.

${ }^{17}$ Appendix A documents possible sample selection effects by comparing observable characteristics for restaurants with missing wages and / or
}

Our data suggest that restaurants in Neuchâtel tend to be slightly smaller, as reflected by both the number of employees per restaurant and restaurant capacity. We note that our employment data aligns closely with official 2016 records from the Federal Statistical Office (2017), which reports 4.98 employee (3.33 FTE) per restaurant on average for the canton of Neuchâtel and 6.51 employees (4.49 FTE) in control areas. The small differences with figures from Table 3 can be explained by the fact that managers and their family members are excluded from our data, but included in official sources. We also observe that control districts feature more ordinary restaurants relative to Neuchâtel, which is consistent with differences in restaurant size (see footnote 8). By contrast, wages, workforce composition, and prices are on average very similar in control districts and in Neuchâtel ${ }^{18}$. Moreover, average prices derived from our sample are in line with GastroNeuchâtel (2018), which reports that the average price of a soda (3dl) in the canton of Neuchâtel is CHF 3.59, CHF 3.32 for a coffee, and CHF 16.82 for the daily special.

Among 52 restaurants located in the canton of Neuchâtel, 24 employ at least one worker paid below minimum wage, and we now discuss exposure to minimum wage regulation. Table 4, panel a, reports the set of pretreatment outcomes discussed above, comparing restaurants in Neuchâtel with no employees paid below the regulatory minimum $(\underline{W}>19.78)$ against those with at least one employee below the regulatory minimum $(\underline{W}<19.78)$. Overall, both subgroups of restaurants are observationally similar, with one important exception:

work-time information against those included in the estimation sample. We show that restaurants with missing wage information are quite similar to those in the estimation sample, while those with missing work-time information tend to include a smaller share of workers under 25 years old.

${ }^{18}$ The difference in the average price of a coffee is statistically significant at a $10 \%$, although the magnitude of the difference is not economically significant. 


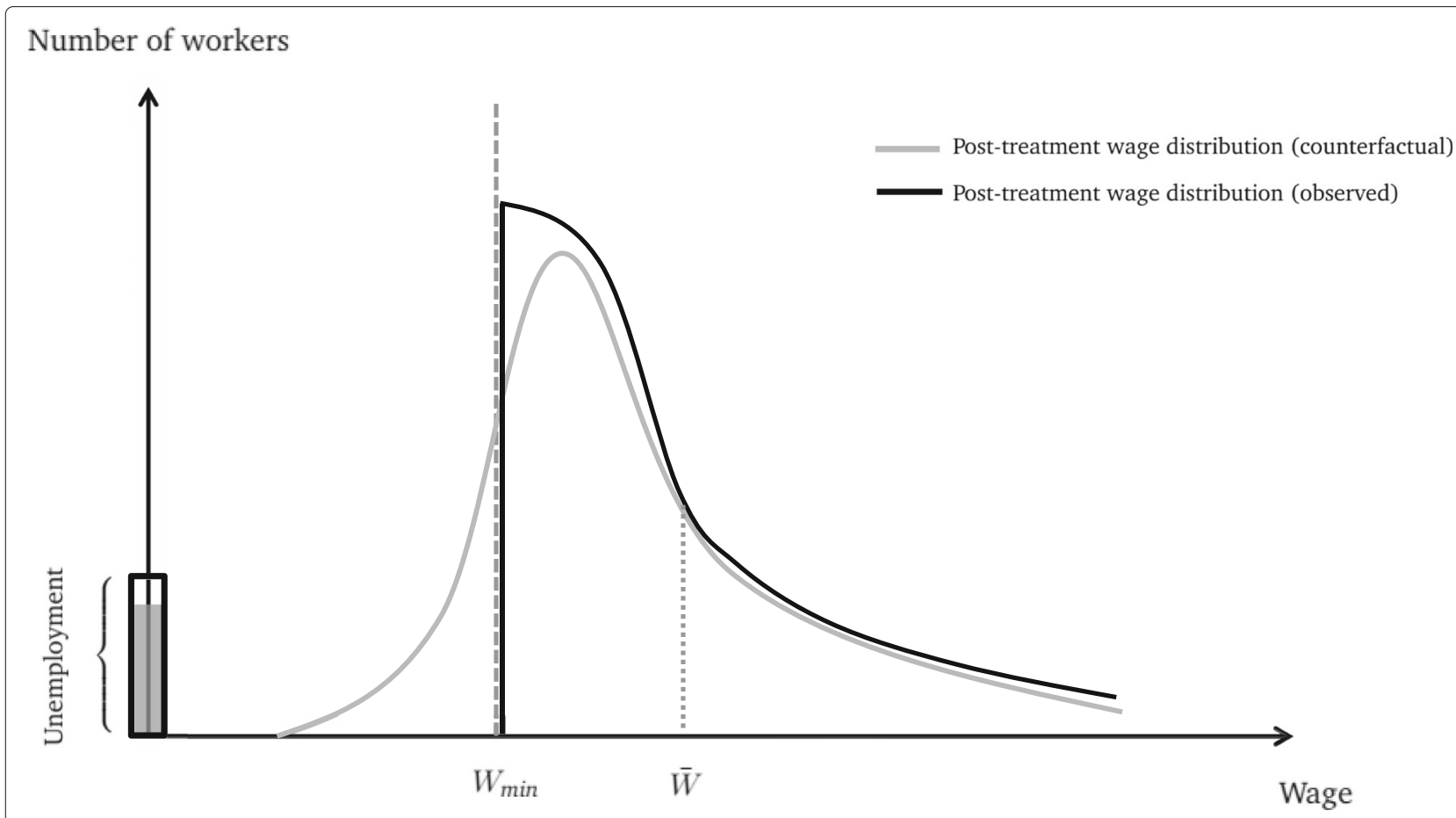

Fig. 3 Illustrative impact of minimum wage regulation on the distribution of wages

Table 3 Pre-treatment outcomes across control and treated areas

\begin{tabular}{|c|c|c|c|c|c|c|c|}
\hline & \multirow[b]{2}{*}{$N$} & \multicolumn{2}{|c|}{ Control districts } & \multicolumn{2}{|c|}{ Neuchâtel } & \multirow[b]{2}{*}{ Diff. } & \multirow[b]{2}{*}{$T$-stat } \\
\hline & & $N$ & Mean & $N$ & Mean & & \\
\hline \multicolumn{8}{|l|}{ Employment and wages } \\
\hline Headcount employment & 94 & 42 & 6.00 & 52 & 3.77 & $-2.23^{* *}$ & $(-2.33)$ \\
\hline FTE employment & 88 & 43 & 4.53 & 45 & 2.98 & $-1.54^{*}$ & $(-1.77)$ \\
\hline Average wage (CHF/hour) & 94 & 42 & 22.74 & 52 & 22.18 & -0.56 & $(-1.13)$ \\
\hline Ordinary restaurants & 94 & 42 & 0.40 & 52 & 0.23 & $-0.17^{*}$ & $(-1.80)$ \\
\hline \multicolumn{8}{|c|}{ Workforce composition (within restaurant shares) } \\
\hline Part-time workers & 94 & 42 & 0.49 & 52 & 0.55 & 0.07 & $(0.88)$ \\
\hline Workers without qualification & 94 & 42 & 0.74 & 52 & 0.75 & 0.01 & $(0.14)$ \\
\hline Young workers ( $<25$ years old) & 94 & 42 & 0.20 & 52 & 0.19 & -0.02 & $(-0.26)$ \\
\hline \multicolumn{8}{|l|}{ Prices (CHF) } \\
\hline $3 \mathrm{dl}$ soda & 94 & 42 & 3.68 & 52 & 3.69 & 0.01 & $(0.11)$ \\
\hline Coffee & 94 & 42 & 3.60 & 52 & 3.46 & $-0.14^{* * *}$ & $(-2.94)$ \\
\hline Daily special & 91 & 42 & 17.94 & 49 & 17.64 & -0.30 & $(-0.39)$ \\
\hline \multicolumn{8}{|l|}{ Restaurant capacity } \\
\hline Seating capacity & 94 & 42 & 113.00 & 52 & 90.33 & $-22.67^{*}$ & $(-1.67)$ \\
\hline Daily meals served (Mon-Thu) & 94 & 42 & 49.68 & 52 & 41.06 & -8.62 & $(-1.02)$ \\
\hline Daily meals served (Fri-Sun) & 94 & 42 & 67.32 & 52 & 47.69 & $-19.63^{*}$ & $(-1.71)$ \\
\hline
\end{tabular}

Notes: This table reports pre-treatment averages in control districts and in Neuchâtel, excluding data for managers and members of their family. FTE employment is based on reported work-time information for each employee and computed only for restaurants with complete working time data. Workers without qualification are employees without a professional degree. Heteroskedasticity-robust $t$-statistics reported. ${ }^{*},{ }^{* *}$, and ${ }^{* * *}$ denote statistical significance at $10 \%, 5 \%$, and $1 \%$ respectively 
Table 4 Exposure to minimum wage regulation for restaurants in Neuchâtel

\begin{tabular}{|c|c|c|c|c|c|c|c|}
\hline & \multirow[b]{2}{*}{$N$} & \multicolumn{2}{|c|}{$\underline{w}>19.78$} & \multicolumn{2}{|c|}{$\underline{w}<19.78$} & \multirow[b]{2}{*}{ Diff. } & \multirow[b]{2}{*}{$T$-stat } \\
\hline & & $N$ & Mean & $N$ & Mean & & \\
\hline \multicolumn{8}{|l|}{$\underline{\text { Panel a: Pre-treatment outcomes }}$} \\
\hline \multicolumn{8}{|l|}{ Employment and wages } \\
\hline Headcount employment & 52 & 28 & 4.00 & 24 & 3.50 & -0.50 & $(-0.65)$ \\
\hline FTE employment & 45 & 26 & 3.30 & 19 & 2.54 & -0.76 & $(-0.98)$ \\
\hline Average wage (CHF/hour) & 52 & 28 & 23.27 & 24 & 20.90 & $-2.38^{* * *}$ & $(-3.84)$ \\
\hline Ordinary restaurants & 52 & 28 & 0.29 & 24 & 0.17 & -0.12 & $(-1.02)$ \\
\hline \multicolumn{8}{|l|}{ Workforce composition (within restaurant shares) } \\
\hline Part-time workers & 52 & 28 & 0.56 & 24 & 0.54 & -0.02 & $(-0.19)$ \\
\hline Workers without qualification & 52 & 28 & 0.76 & 24 & 0.73 & -0.03 & $(-0.34)$ \\
\hline Young workers $(<25$ years old) & 52 & 28 & 0.16 & 24 & 0.23 & 0.07 & $(0.82)$ \\
\hline \multicolumn{8}{|l|}{ Prices (CHF) } \\
\hline $3 \mathrm{dl}$ soda & 52 & 28 & 3.69 & 24 & 3.69 & -0.01 & $(-0.05)$ \\
\hline Coffee & 49 & 27 & 3.43 & 22 & 3.49 & 0.06 & $(0.85)$ \\
\hline Daily special & 52 & 28 & 17.73 & 24 & 17.66 & 0.03 & $(0.04)$ \\
\hline \multicolumn{8}{|l|}{ Restaurant capacity } \\
\hline Seating capacity & 52 & 28 & 94.18 & 24 & 85.83 & -8.35 & $(-0.64)$ \\
\hline Daily meals served (Mon-Thu) & 52 & 28 & 47.82 & 24 & 33.17 & -14.65 & $(-1.63)$ \\
\hline Daily meals served (Fri-Sun) & 52 & 28 & 60.00 & 24 & 33.33 & $-26.67^{* *}$ & $(-2.25)$ \\
\hline \multicolumn{8}{|l|}{ Panel (b): Minimum wage exposure } \\
\hline Lowest wage ( $\underline{W}, \mathrm{CHF} /$ hour $)$ & 52 & 28 & 22.67 & 24 & 18.49 & $-4.18^{* * *}$ & $(-10.57)$ \\
\hline Share of workers below $\underline{W}$ & 52 & 28 & 0.00 & 24 & 0.51 & $0.51^{* * *}$ & $(9.22)$ \\
\hline Minimum wage gap (\% of total wage bill) & 45 & 26 & 0.00 & 19 & 0.04 & $0.04^{* * *}$ & $(4.14)$ \\
\hline
\end{tabular}

Notes: This table reports pre-treatment averages for restaurants in Neuchâtel with and without employees paid below $W=19.78$, excluding data for managers and members of their family. $W$ denotes the lowest hourly wage rate in restaurant. FTE employment is based on reported work-time information for each employee and computed only for restaurants with complete working time data. Workers without qualification are employees without a professional degree. Heteroskedasticity-robust t-statistics reported. ${ }^{*}$,

**, and ${ }^{* * *}$ denote statistical significance at $10 \%, 5 \%$, and $1 \%$, respectively

restaurants with pre-treatment wages below the regulatory minimum serve significantly less meals, with the difference for meals served during weekends reaching almost $50 \%$ (60 meals on average for restaurants with $W>19.78$ vs. 33 for those with $\underline{W}<19.78$ ). Because restaurants are otherwise comparable in terms of employment and seating capacity, one implication is that restaurants affected by minimum wage regulation in Neuchâtel appear to be less profitable even before the regulation is enforced ${ }^{19}$.

In panel b of Table 4, we provide evidence about the bite of minimum wage regulation for restaurants in Neuchâtel. Our data suggest that the lowest wage paid by restaurants with $\underline{W}<19.78$ is, on average, CHF 18.51 per hour, which is around $20 \%$ below what we observe in restaurants with no employees paid below minimum wage. Moreover, the

\footnotetext{
${ }^{19}$ We note that $17 \%$ of restaurants with $\underline{W}<19.78$ are ordinary restaurants, which signals some degree of non-compliance with the CLA. Similarly, among 42 restaurants in control districts, 13 employ workers paid below CHF 19.78 per hour, and among these three are ordinary restaurants (23\%).
}

within-restaurant share of workers affected by minimum wage regulation is around $50 \%$, which implies that affected restaurants have to increase wages for 1.75 workers on average.

A related measure for the intensity (or severity) of the minimum wage bite is the pre-treatment minimum wage gap, defined as the total wage increase that is needed to reach the legal minimum (Giupponi and Machin 2018):

Minimum wage gap $_{i}=\frac{\sum_{f} h_{i f} \cdot \max \left\{W_{\text {min }}-W_{i f}, 0\right\}}{\sum_{f} h_{i f} W_{i f}}$,

where $h_{i f}$ is weekly hours worked by worker $f$ in restaurant $i$. In our data, the average minimum wage gap is $3.81 \%$ of the total wage bill ( $0.4 \%$ among ordinary restaurants). As shown in Fig. 4, however, the distribution for the minimum wage gap is highly skewed, with three restaurants 


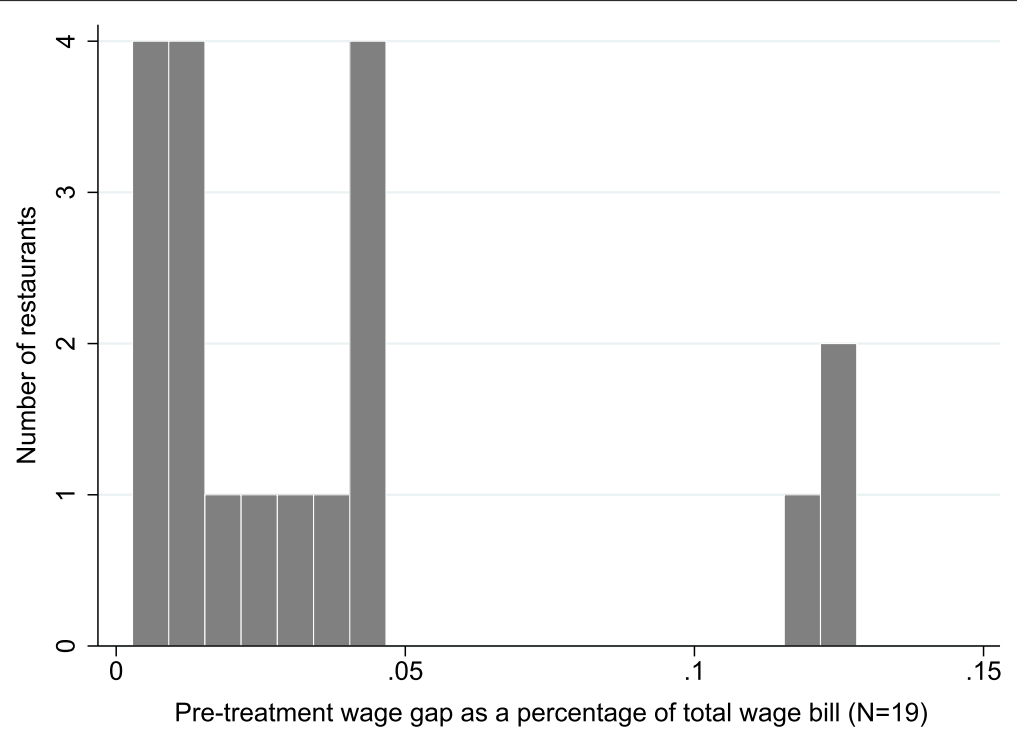

Fig. 4 Minimum wage gap among restaurants in Neuchâtel (Eq. 5)

above $10 \%$ and all the other restaurants below $5 \%$ (median: $1.51 \%)^{20}$.

In sum, while the bite of minimum wage regulation can be substantial for a small number of restaurants, for the industry as a whole the impact on costs is expected to be limited, which is consistent with the report by the Council of State of Neuchâtel (2013).

\subsection{Impacts of minimum wage regulation}

This section reports the main results derived from our survey. First, we provide evidence about the impact of minimum wage regulation on wages paid by restaurants. Second, we consider employment effects using both a distribution-based approach and regression-based DD analysis for headcount and FTE employment. Third, we document impacts on restaurant-level workforce composition. Finally, we estimate the effect of minimum wage regulation on prices.

\subsubsection{Regulatory impacts on wages}

In Fig. 5, we start by reporting evidence on how the share of employees paid below CHF 19.78 evolves over time. In Neuchâtel, 19\% of workers are paid below CHF 19.78 in summer 2017, a proportion that drops to $4.8 \%$ in spring 2018. Projections for summer 2018 suggest a slight increase to $5.8 \%$. The fact that a small share of restaurants (around 11\%) still employ workers paid below the regulatory minimum after enforcement is in line with anecdotal evidence by Giroud (2018) and is a common feature in

\footnotetext{
${ }^{20}$ The three restaurants with a relatively large minimum wage gap are included in the analysis below, as they represent a significant share of affected restaurants and are therefore not treated as outliers. We note, however, that excluding them from the analysis does not alter our results and conclusions.
}

minimum wage research (Cengiz et al. 2019). In control districts, the corresponding shares first decrease from 13.4 to $10.2 \%$, before increasing again to $12.6 \%$.

Next, Fig. 6 reports the distribution of hourly wages across regions for restaurants with at least one employee paid below minimum wage (panels $a$ and $b$ ) and for restaurants with no employees paid below minimum wage (panels $\mathrm{c}$ and d). We specify wage bins of CHF 2, so that the discretized wage distribution includes a total of eight bins. In Neuchâtel (panel a), the number of workers with wages below the regulatory minimum declines from 36 (pre-treatment, summer 2017) to 9 (post-treatment, spring 2018), and is expected to increase to 11 (posttreatment, summer 2018). The number of workers in the wage bin just above minimum wage increases from 12 in summer 2017 to 38 and 41 in spring and summer 2018, respectively. Interestingly, the number of workers in the subsequent wage bin (CHF 21.78-23.77) declines, while it increases again in bin CHF 23.78-25.77. This indicates the possible presence of ripple effects, something we discuss in more detail below.

By contrast, the wage distributions reported in panels (b), (c), and (d) remain very stable, especially when comparing summer 2017 with summer 2018 projections, which suggests the present of seasonal effects. In particular, the fact that the wage distribution of restaurants with low-wage workers located in control districts does not change across survey waves indicates that minimum wage regulation in Neuchâtel has no perceptible impact on wages set in control districts. This can be interpreted as evidence that cross-border spillovers are likely small.

Table 5 reports OLS regression results quantifying regulatory impacts on restaurant-level wages (Eq. 1). In 


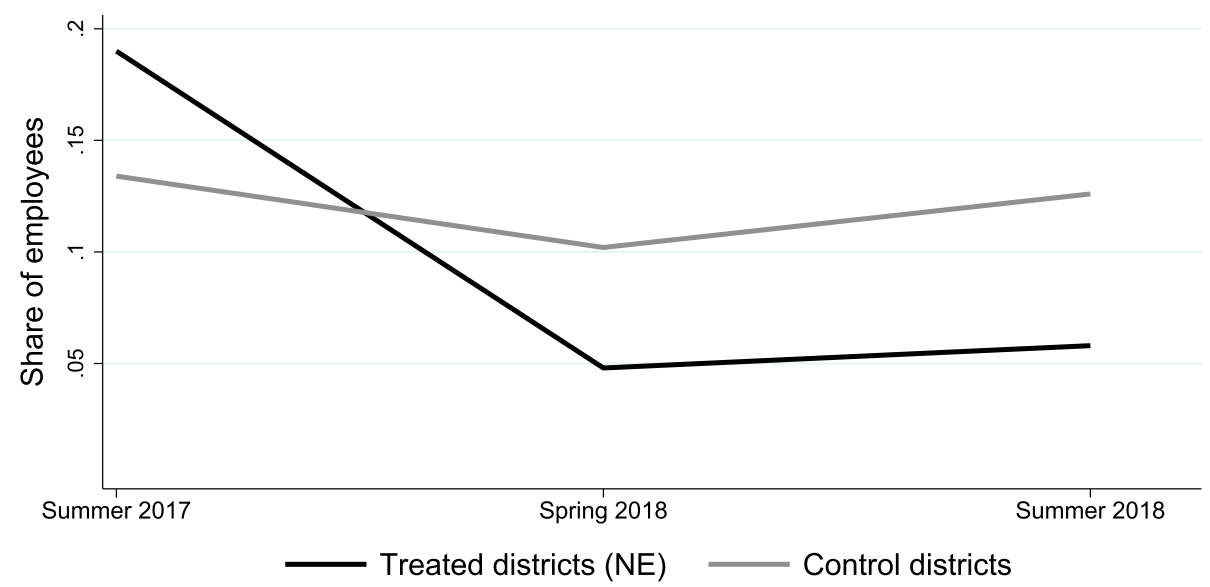

Fig. 5 Share of employees paid below minimum wage

columns (1) and (2), the outcome variable is an indicator variable equal to one if the restaurant employs workers paid below CHF 19.78 per hour, zero otherwise (denoted $\left.\mathbb{1}_{[W<19.78]}\right) .{ }^{21}$ In columns (3) and (4), the outcome variable is the natural logarithm of the lowest hourly wage paid by the restaurant (denoted $\ln (\underline{W})$ ). In columns (5) and (6), the outcome is the natural logarithm of average hourly wages paid in the restaurant (denoted $\ln (\operatorname{avg.W})$ ). All specifications include restaurants and time fixed effects, and in columns (2), (4), and (6), we further control for potential local demand shocks by including the average number of meals served ("Daily meals served (Mon-Thu)" and "Daily meals served (Fri-Sun)"). Standard errors clustered at the restaurant level are reported in parentheses.

Results in columns (1) and (2) suggest that minimum wage regulation induces to a large and statistically significant reduction of the proportion of restaurants paying less than CHF 19.78 per hour. Moreover, time-fixed effects $\left(\delta_{\text {spring }}\right.$ and $\left.\delta_{\text {summer }}\right)$ indicate that this proportion also declines in the control group, suggesting that it would have declined in Neuchâtel even without minimum wage regulation. We also observe that the estimated treatment effect is larger for summer employment, which suggests that compliance increases with time. Therefore, while the possibility of strategic misreporting of wages and measurement error in the second wave of the survey should be kept in mind, as managers may want to signal compliance with the regulation, measuring variation in the proportion of restaurants with $W<19.78$ is consistent with evidence that firms' regulatory compliance increases with time (see Doyle 2005). Controlling for demand shocks does not affect the results in any significant manner.

\footnotetext{
${ }^{21}$ For restaurants in Neuchâtel, post-treatment outcome essentially measures compliance with the regulation. Also, note that by applying OLS to a binary outcome, we implicitly use a linear probability model. Estimating instead a logit or probit model and evaluating average marginal effects yields very similar results.
}

We further find a statistically significant impact of minimum wage regulation on the lowest wage paid by restaurants, which increase by around $2 \%$ on average relative to control. Here, again there is evidence of a positive trend in control areas, which suggests that $\underline{W}$ increases by 1 or $2 \%$ in restaurants not affected by regulation. By contrast, estimates for the impact of regulation on average hourly wages paid by restaurants is small and not statistically different from zero, with point estimates between 0.1 and $0.5 \%$.

\subsubsection{Regulatory impacts on employment}

Having discussed the impact of regulation on wages, we now proceed with the estimation of employment effects. We start with the distributional analysis described in Section 3.2.2 and illustrate the results graphically in Fig. $7^{22}$. More specifically, panel a provides observed and counterfactual wage distributions for spring 2018 derived from data on 846 employees distributed over the two survey waves. Recall that the counterfactual distribution is an estimate of what would have been observed in Neuchâtel in the absence of minimum wage regulation (Eq. 3). In panel $\mathrm{b}$, we report the difference between actual and counterfactual distributions $\left(\rho^{k}\right.$, Eq. 4$)$, quantifying policy effects for employment in each wage bin. We also draw cumulative employment effects as a solid line for increasing values of $\bar{W}$. Panels c and d provide the same information for summer 2018 projections.

A comparison of observed and counterfactual distribution of wages for spring 2018 in the canton of Neuchâtel (panel a) confirms a substantial decline in the share of employees paid below CHF 19.78, and an increase in the wage bin just above the regulatory minimum. Employment effects across wage bins (panel b) suggest that most

\footnotetext{
${ }^{22}$ Consistent with the analysis elsewhere in the paper, we exclude data for managers and members of their family. In Appendix B, we report the data underlying these figures.
} 


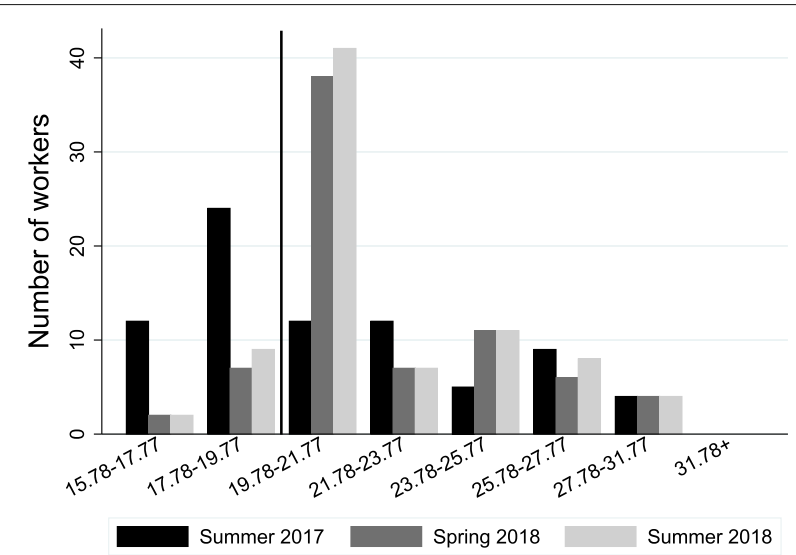

(a) Neuchâtel, restaurants with at least one worker with pretreatment wage below CHF 19.78 per hour

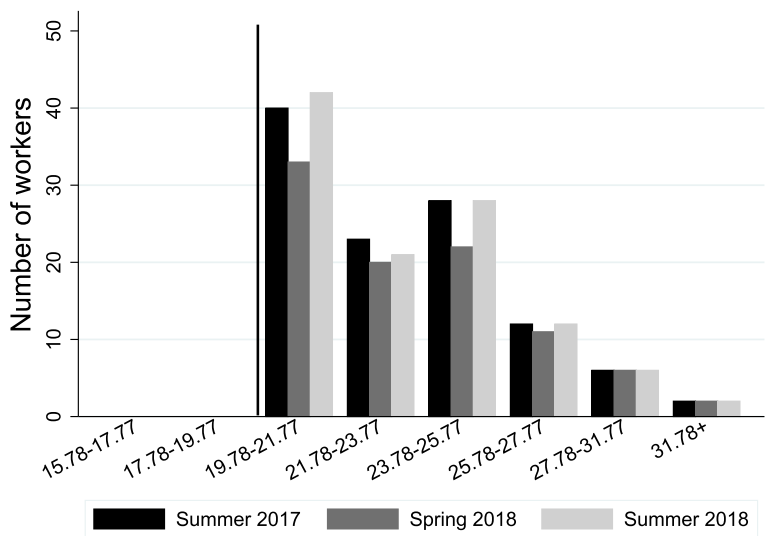

(c) Neuchâtel, restaurants with no workers with pretreatment wage below CHF 19.78 per hour

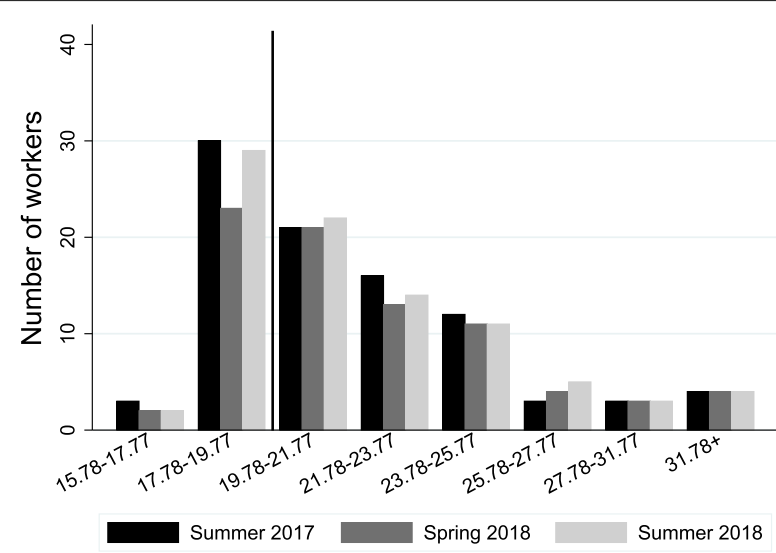

(b) Control districts, restaurants with at least one worker with pretreatment wage below CHF 19.78 per hour

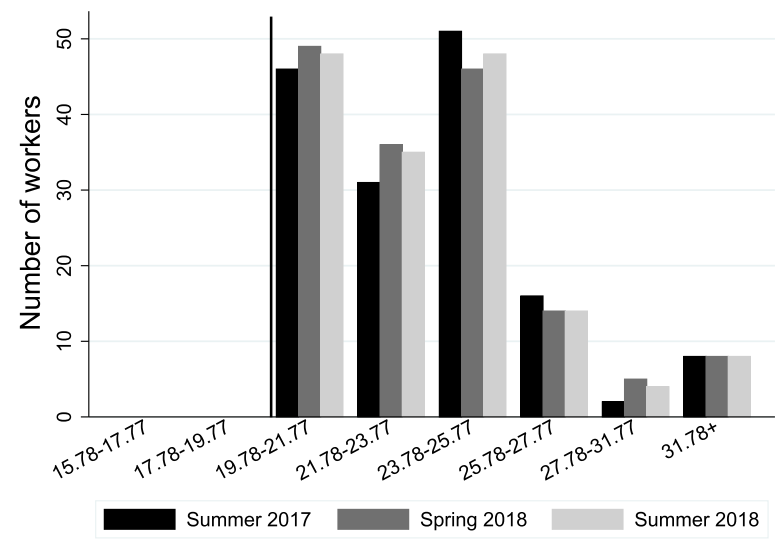

(d) Control districts, restaurants with no workers with pretreatment wage below CHF 19.78 per hour

Fig. 6 Wage distribution (CHF/hour) for restaurants with and without pretreatment wages below the regulatory minimum

of sub-minimum wage jobs have been preserved, although cumulative employment change for $\bar{W}=21.77$ is $-2.6 \%$. However, data for summer 2018 (panels c and d) show a cumulative decline of $-12.4 \%$ in wage bins below the regulatory minimum, and an increase of $15.2 \%$ in the bin just above. The associated cumulative employment gain of $2.8 \%$ for $\bar{W}=21.77$. Because the baseline pre-treatment wage distribution reflects summer 2017 employment, this suggests that the decline in employment for spring 2017 captures seasonal variability.

Consistent with the discussion of Fig. 6, the fourth wage bin shows a reduction of employment by around 5\%, whereas the fifth bin shows an increase in employment by around 2\% in spring 2018 and 5\% in summer 2018 . This suggests that workers with hourly wages up to $\mathrm{CHF}$ 6 above the regulatory minimum are affected by the regulation. By contrast, subsequent wage bins only show small differences and are thus less relevant. Overall, cumulative employment impacts suggest a reduction of $-8.7 \%$ for spring 2018 and an increase of 1.7\% for summer 2018. This again suggests that negative estimates for spring 2018 likely reflect seasonality effects not related to minimum wage regulation, whereas those for summer 2018 show no impact of regulation on sectoral employment.

To further document these results, we now move to a restaurant-level DD analysis, and Table 6 reports OLS 
Table 5 Restaurant-level impacts on hourly wages from OLS regressions

\begin{tabular}{|c|c|c|c|c|c|c|}
\hline & \multicolumn{2}{|l|}{$\mathbb{1}_{[\underline{W}<19.78]}$} & \multicolumn{2}{|l|}{$\ln (\underline{W})$} & \multicolumn{2}{|c|}{$\ln (\operatorname{avg} . W)$} \\
\hline & (1) & (2) & (3) & (4) & (5) & (6) \\
\hline \multirow[t]{2}{*}{$D D_{\text {spring }}$} & $-0.251^{* * *}$ & $-0.263^{* * *}$ & $0.021^{*}$ & $0.022^{*}$ & 0.002 & 0.002 \\
\hline & $(0.081)$ & $(0.080)$ & $(0.012)$ & $(0.012)$ & $(0.012)$ & $(0.012)$ \\
\hline \multirow[t]{2}{*}{$D D_{\text {summer }}$} & $-0.299 * * *$ & $-0.310^{* * *}$ & $0.025^{* *}$ & $0.025^{* *}$ & 0.005 & 0.005 \\
\hline & $(0.075)$ & $(0.075)$ & $(0.012)$ & $(0.012)$ & $(0.012)$ & $(0.012)$ \\
\hline \multirow[t]{2}{*}{$\delta_{\text {spring }}$} & $-0.095^{* *}$ & $-0.093^{* *}$ & $0.019^{* * *}$ & $0.020^{* * *}$ & $0.019^{* *}$ & $0.019^{*}$ \\
\hline & $(0.046)$ & $(0.045)$ & $(0.006)$ & $(0.006)$ & $(0.009)$ & $(0.010)$ \\
\hline \multirow[t]{2}{*}{$\delta_{\text {summer }}$} & -0.048 & -0.045 & $0.015^{* * *}$ & $0.016^{* * *}$ & 0.014 & 0.014 \\
\hline & $(0.033)$ & $(0.032)$ & $(0.005)$ & $(0.006)$ & $(0.009)$ & $(0.009)$ \\
\hline Controls & $N$ & Y & $N$ & Y & $N$ & Y \\
\hline$R^{2}$ & 0.296 & 0.310 & 0.216 & 0.225 & 0.101 & 0.103 \\
\hline$N$ restaurants & 94 & 94 & 94 & 94 & 94 & 94 \\
\hline
\end{tabular}

Notes: OLS regression coefficients reported. In columns (1) and (2), the outcome is a binary variable equal to one if at least one employee earns less than CHF 19.78 per hour, zero otherwise ( $\underline{W}$ denotes the lowest hourly wage rate in restaurant). In columns (3) and (4), the outcome is the natural logarithm of $\underline{W}$. In columns (5) and (6), the outcome is the natural logarithm of average hourly wages paid in the restaurant. All specifications include restaurant and time fixed effects, and columns (2), (4), and (6) include control variables "Daily meals served (Mon-Thu)" and "Daily meals served (Fri-Sun)." Excludes data for managers and members of their family. Robust standard errors clustered at the restaurant level reported in parentheses. ${ }^{*}{ }^{* *}$, and ${ }^{* * *}$ denote statistical significance at $10 \%, 5 \%$, and $1 \%$, respectively

regression results quantifying the impact of minimum wage regulation in Neuchâtel on (log-)headcount employment (columns 1 and 2) and (log-)FTE employment (columns 5 and 6). Considering FTE employment impacts is important because about half of the employees in our dataset work part time (see Table 3), although we lose observations for restaurants that do not provide complete information for their employees (managers and members of their family are still excluded). All specifications include restaurant and time fixed effects, and columns (2) and (4) further include control variables ("Daily meals served (Mon-Thu)" and "Daily meals served (Fri-Sun)"). Robust standard errors clustered at the restaurant level are reported in parentheses.

Across all specifications, DD estimates reported in the first two rows do not suggest a statistically significant effect of minimum wage regulation on average employment in restaurants. For spring 2018, point estimates for headcount employment suggest an increase of restaurantlevel employment of around 3\% on average, whereas FTE results suggest a negative impact of around $4 \%$. For summer 2018, point estimates are positive for both headcount and FTE employment. These results are consistent with those observed for the distributional analysis, suggesting small negative impacts for spring 2018 potentially reflecting seasonal variability, while those for summer 2018 make negative impacts very unlikely ${ }^{23}$.

\footnotetext{
${ }^{23}$ In the absence of more than one pre-treatment period, we cannot discriminate between specifications in levels or in logs. In light of pre-treatment differences documented in Table 3, our preferred specification uses a log-transformed outcome variable. Nevertheless, we obtain comparable results when employment is measured in levels, with slightly negative
}

\subsubsection{Regulatory impacts on workforce composition}

Next, we quantify the impact of minimum wage regulation on employee characteristics at the restaurant level (still excluding managers and members of their family). In Table 7, we report OLS regression results for three different measures of workforce composition. First, in columns (1) and (2), we focus on the within-restaurant share of workers with part-time contracts ${ }^{24}$. Second, columns (3) and (4) consider the share of employees without a professional qualification. The third outcome, reported in columns (5) and (6), is the share of workers that are less than 25 years old. Restaurant and time fixed effects are included in all specifications, and control variables "Daily meals served (Mon-Thu)" and "Daily meals served (Fri-Sun)" are included in columns (2), (4), and (6). Robust standard errors clustered at the restaurant level are reported in parentheses.

Starting with part-time employment, time fixed effects show evidence of a positive trend in the share of parttime employees. However, while the increase has been more pronounced for restaurants in Neuchâtel, the difference with control areas is not statistically significantly different from zero. By contrast, we find some suggestive evidence that the proportion of workers with no professional qualification increases by around 5\% points in Neuchâtel relative to control (one point estimate for summer 2018 reaches statistical significance at the $10 \%$

employment effects for spring 2018 and zero or even positive employment impacts for summer 2018. See Appendix C.

${ }^{24}$ We again apply OLS to a limited dependent variable. Using a non-linear (e.g., logistic) transformation to bound the outcome variable between 0 and 1 yields very similar results. 


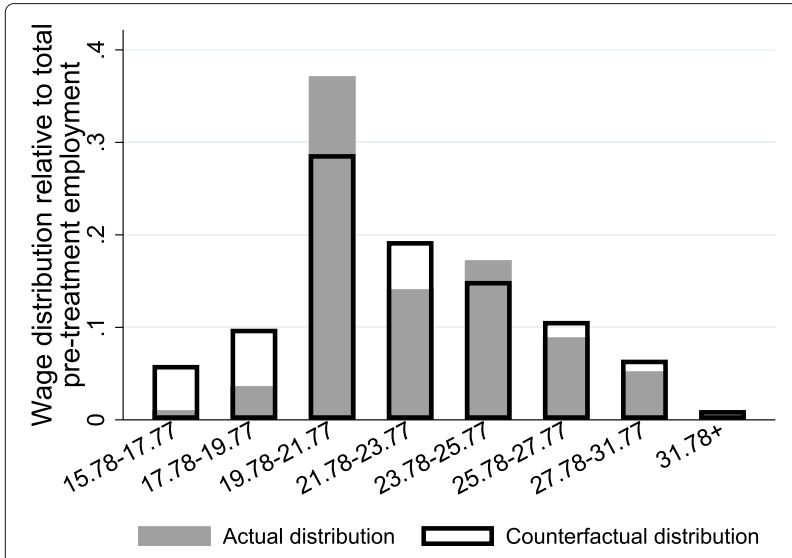

(a) Actual and counterfactual wage distributions, spring 2018

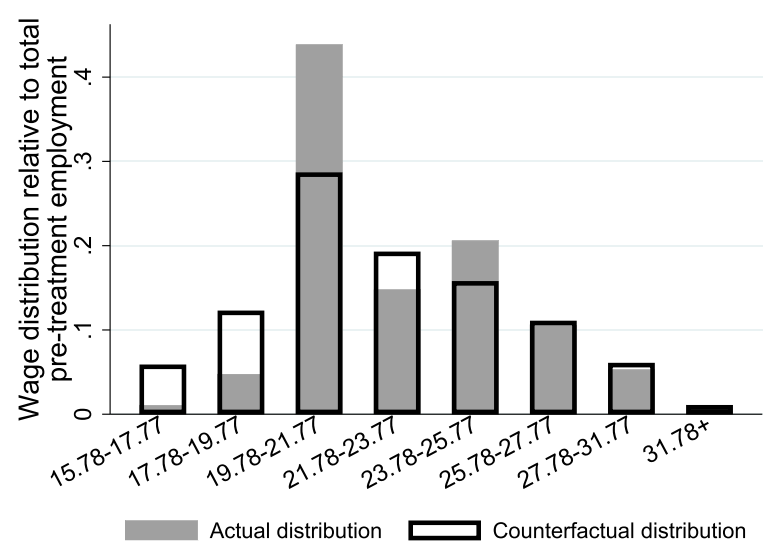

(c) Actual and counterfactual wage distributions, summer 2018

Fig. 7 Employment effects by wage bins in Neuchâtel

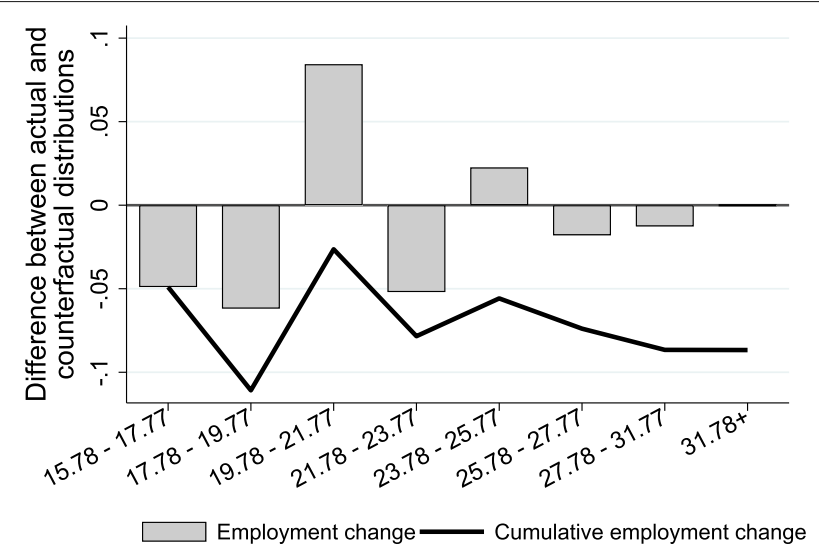

(b) Difference between actual and counterfactual wage distributions, spring 2018

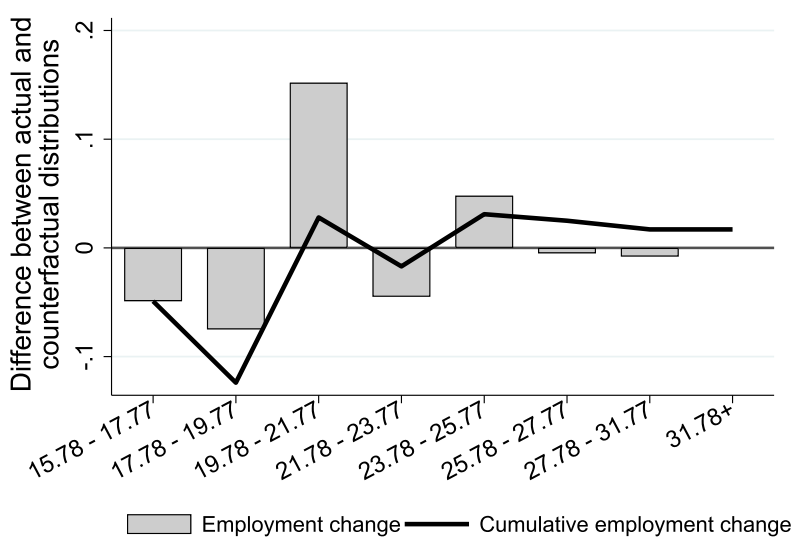

(d) Difference between actual and counterfactual wage distributions, summer 2018 threshold). While we emphasize that the confidence intervals are quite wide, this suggests that higher wages for low-wage employees may induce restaurants to hire relatively more non-qualified workers. Lastly, we find no evidence that the share of young workers changes across survey waves.

\subsubsection{Regulatory impacts on prices}

Our final set of results quantifies the impact of minimum wage regulation on the price of three standard products sold by restaurants in Switzerland. Specifically, Table 8 reports regression-based DD evidence for the price of a 3dl soda (columns 1 and 2), a cup of coffee (columns 3 and 4), and the daily special (columns 5 and 6). In all specifications, the outcome variable is log-transformed, and we include restaurant and time fixed effects. In columns
(2), (4), and (6), we further control for demand shocks. Cluster-robust standard errors are reported in parentheses. Note also that we do not separately measure prices in spring and summer 2018, so that we only have one post-treatment observation.

For all three products, we find no evidence of price impacts, as estimates are all small in magnitude and not statistically significantly different from zero. We also do not detect a trend in the control group, as post-treatment fixed effects are also very close to zero ${ }^{25}$.

\section{Discussion}

Overall, three main insights can be derived from our empirical results. First, our data confirm that mini-

\footnotetext{
${ }^{25}$ The results are similar for corresponding linear specifications, see Appendix
} 
Table 6 Restaurant-level impacts on employment from OLS regressions

\begin{tabular}{|c|c|c|c|c|}
\hline & \multicolumn{2}{|c|}{ In(Headcount) } & \multicolumn{2}{|l|}{$\ln (F T E)$} \\
\hline & (1) & (2) & (3) & (4) \\
\hline \multirow[t]{2}{*}{$D D_{\text {spring }}$} & 0.029 & 0.038 & -0.046 & -0.041 \\
\hline & $(0.062)$ & $(0.061)$ & $(0.060)$ & $(0.059)$ \\
\hline \multirow[t]{2}{*}{$D D_{\text {summer }}$} & 0.093 & 0.102 & 0.021 & 0.026 \\
\hline & $(0.062)$ & $(0.065)$ & $(0.058)$ & $(0.059)$ \\
\hline \multirow[t]{2}{*}{$\delta_{\text {spring }}$} & -0.047 & -0.050 & -0.055 & -0.058 \\
\hline & $(0.039)$ & $(0.042)$ & $(0.034)$ & $(0.038)$ \\
\hline \multirow[t]{2}{*}{$\delta_{\text {summer }}$} & -0.003 & -0.006 & -0.022 & -0.025 \\
\hline & $(0.042)$ & $(0.046)$ & $(0.036)$ & $(0.040)$ \\
\hline Controls & $N$ & Y & $N$ & Y \\
\hline$R^{2}$ & 0.054 & 0.068 & 0.062 & 0.066 \\
\hline$N$ restaurants & 94 & 94 & 88 & 88 \\
\hline
\end{tabular}

Notes: OLS regression coefficients reported. In columns (1) and (2), the outcome is the natural logarithm of headcount employment by restaurants. In columns (3) and (4), the outcome is the natural logarithm of FTE employment, which is based on reported work-time information for each employee and computed only for restaurants with complete working time data. All specifications include restaurant fixed effects and period fixed effects. Columns (2) and (4) include control variables "Daily meals served (Mon-Thu)" and "Daily meals served (Fri-Sun)." We exclude data for managers and members of their family from the estimation. Robust standard errors clustered at the restaurant level reported in parentheses. ${ }^{*}, * *$, and ${ }^{* * *}$ denote statistical significance at $10 \%, 5 \%$, and $1 \%$, respectively

mum wage regulation has significantly reduced the number of low-wage employees in Neuchâtel. Second, this decline has been compensated by a significant increase in the number of employees paid just above minimum wage. This suggests that employment is not used as a margin of adjustment by restaurants in Neuchâtel, which is consistent with a large body of empirical research. Comparing summer 2017 and expectations about 2018 employment, our data even suggest a small increase of restaurant-level employment. Third, the data indicate the presence of ripple effects, whereby some workers with pre-treatment wages above the regulatory minimum are pushed into higher wage bins (see Fig. 6, panel a, and Fig. 7, panels a and c).

While our survey provides a first set of empirical results on how restaurants are affected by minimum wage regulation in Neuchâtel, causal interpretation of our DD results is subject to a number of limitations. First, a DD

Table 7 Impacts on workforce composition (within restaurant shares) from OLS regressions

\begin{tabular}{|c|c|c|c|c|c|c|}
\hline & Part-tin & & Worke & & Young & \\
\hline & (1) & (2) & (3) & (4) & (5) & (6) \\
\hline$D D_{\text {spring }}$ & -0.005 & 0.004 & 0.047 & 0.057 & -0.029 & -0.030 \\
\hline & $(0.055)$ & $(0.054)$ & $(0.038)$ & $(0.039)$ & $(0.065)$ & $(0.067)$ \\
\hline$D D_{\text {summer }}$ & -0.005 & 0.004 & 0.054 & $0.065^{*}$ & -0.022 & -0.024 \\
\hline & $(0.055)$ & $(0.055)$ & $(0.037)$ & $(0.038)$ & $(0.059)$ & $(0.060)$ \\
\hline$\delta_{\text {spring }}$ & $0.073^{*}$ & $0.076^{*}$ & 0.006 & -0.009 & -0.022 & -0.023 \\
\hline & $(0.040)$ & $(0.040)$ & $(0.020)$ & $(0.021)$ & $(0.042)$ & $(0.046)$ \\
\hline$\delta_{\text {summer }}$ & $0.086^{* *}$ & $0.089^{* *}$ & 0.014 & -0.002 & 0.008 & 0.007 \\
\hline & $(0.040)$ & $(0.042)$ & $(0.020)$ & $(0.020)$ & $(0.033)$ & $(0.037)$ \\
\hline Controls & $N$ & Y & $N$ & Y & $N$ & Y \\
\hline$R^{2}$ & 0.078 & 0.124 & 0.057 & 0.099 & 0.014 & 0.015 \\
\hline$N$ restaurants & 94 & 94 & 94 & 94 & 94 & 94 \\
\hline
\end{tabular}

Notes: OLS regression coefficients reported. In columns (1) and (2), the outcome the within-restaurant share of employees with part-time contracts. In columns (3) and (4), the outcome is the share of employees without a professional degree. In columns (5) and (6), the outcome is the share of workers that are less than 25 years of age. All

specifications include restaurant fixed effects and time fixed effects. Columns (2), (4), and (6) include control variables "Daily meals served (Mon-Thu)" and "Daily meals served (Fri-Sun)." We exclude data for managers and members of their family from the estimation. Robust standard errors clustered at the restaurant level reported in parentheses. *, **, and *** denote statistical significance at $10 \%, 5 \%$, and $1 \%$, respectively 
Table 8 Restaurant-level impacts on prices from OLS regressions

\begin{tabular}{|c|c|c|c|c|c|c|}
\hline & \multicolumn{2}{|c|}{ In(Price soda) } & \multicolumn{2}{|c|}{ In(Price coffee $)$} & \multicolumn{2}{|c|}{ In(Price daily special) } \\
\hline & $(1)$ & $(2)$ & (3) & (4) & $(5)$ & (6) \\
\hline \multirow[t]{2}{*}{$D D_{\text {post }}$} & -0.002 & 0.0003 & 0.007 & 0.008 & 0.003 & 0.003 \\
\hline & $(0.009)$ & $(0.009)$ & $(0.008)$ & $(0.009)$ & $(0.006)$ & $(0.006)$ \\
\hline \multirow[t]{2}{*}{$\delta_{\text {post }}$} & 0.008 & 0.006 & -0.003 & -0.004 & 0.004 & 0.004 \\
\hline & $(0.005)$ & $(0.006)$ & $(0.008)$ & $(0.007)$ & $(0.004)$ & $(0.004)$ \\
\hline Controls & $N$ & Y & $N$ & Y & $N$ & Y \\
\hline$R^{2}$ & 0.022 & 0.049 & 0.009 & 0.016 & 0.047 & 0.049 \\
\hline$N$ restaurants & 94 & 94 & 94 & 94 & 91 & 91 \\
\hline
\end{tabular}

Notes: OLS regression coefficients reported. In columns (1) and (2), the outcome is the natural logarithm of the price of a $3 \mathrm{dl}$ soda. In columns ( 3 ) and (4), the outcome is the natural logarithm of the price of a coffee. In columns (5) and (6), the outcome is the natural logarithm of the price of the daily special. All specifications include restaurant and period fixed effects, and columns (2), (4), and (6) include control variables "Daily meals served (Mon-Thu)" and "Daily meals served (Fri-Sun)." Robust standard errors clustered at the restaurant level reported in parentheses. *,**, and *** denote statistical significance at $10 \%, 5 \%$, and $1 \%$, respectively

approach requires an assumption that restaurants in control districts can inform a counterfactual for restaurants in Neuchâtel. In other words, the changes observed in control districts must be informative about what would have happened in Neuchâtel in the absence of minimum wage regulation. This assumption motivates our choice of geographically proximate regions (Allegretto et al. 2017), and Fig. 2 provides some evidence that the regions considered follow similar unemployment trends. However, this evidence is only indirect, and our data does not allow us to directly test whether this assumption holds for the set of outcomes we consider.

A second potential caveat associated with the use of control districts to estimate counterfactual outcomes is that it necessitates an assumption of no spillovers across regions. This assumption would be violated if restaurants in control districts were also affected by the regulation, which could be the case if they draw their labor force on the same local labor market, for example. While our results suggest that wages have increased in control districts over the period we consider, evidence from the distribution of hourly wages in control districts (Fig. 6, panel b) shows little evidence about a systematic response by restaurants with workers below the regulatory minimum imposed in Neuchâtel. However, because cross-border spillovers would tend to bias our estimates towards zero, DD estimates should be interpreted with caution.

Finally, anticipation effects may also affect our results. As discussed above, minimum wage regulation was initially supported by voters as early as 2011, and the decision of the Supreme Court came before the first wave of the survey. Some restaurants in Neuchâtel may have anticipated enforcements of the regulation before the first wave of our survey. In turn, adjustments before the first wave of the survey would imply that our results tend to underestimate the true effects of minimum wage regulation in the canton of Neuchâtel.

\section{Concluding comments}

In this paper, we have provided a first set of quantitative results on how restaurants in the Swiss canton of Neuchâtel are affected by the introduction of minimum wage regulation. We have designed a two-wave survey administered in Neuchâtel and geographically proximate districts of neighboring cantons, allowing us to gather rich firm-worker data, including detailed employee-level characteristics. Based on this, we have quantified the bite of minimum wage regulation for the restaurant industry in Neuchâtel, one of the most exposed sector in this canton, and documented how wages, employment, workforce composition, and prices changed after enforcement of minimum wage regulation.

The main objective of this work has been to provide empirical evidence that can be informative in the Swiss context. This is important because several other Swiss cantons are in the process of voting or contemplating the introduction of minimum wage regulation. We emphasize that the level of minimum wage introduced in Neuchâtel is relatively close to the CLA, which implies small adjustments for restaurants. Further empirical evidence, including from other data sources, is therefore warranted.

In particular, we report some evidence that the share of part-time workers has increased after the introduction of the policy. Whether this adjustment mechanism is important quantitatively and statistically remains an open question. Moreover, our data shows that restaurants in Neuchâtel with pretreatment wages below the regulatory minimum have a lower ratio of meals served to seating capacity. This could suggest that restaurants affected by minimum wage regulation are less profitable to start with, so that regulation could affect industry dynamics over the longer run. Results from our survey therefore only provide a first step in understanding minimum wage regulation in Switzerland and should be complemented by additional long-run evidence on industry dynamics. 


\section{Appendix A}

Table 9 Pre-treatment outcomes for restaurants with missing wage and work-time information

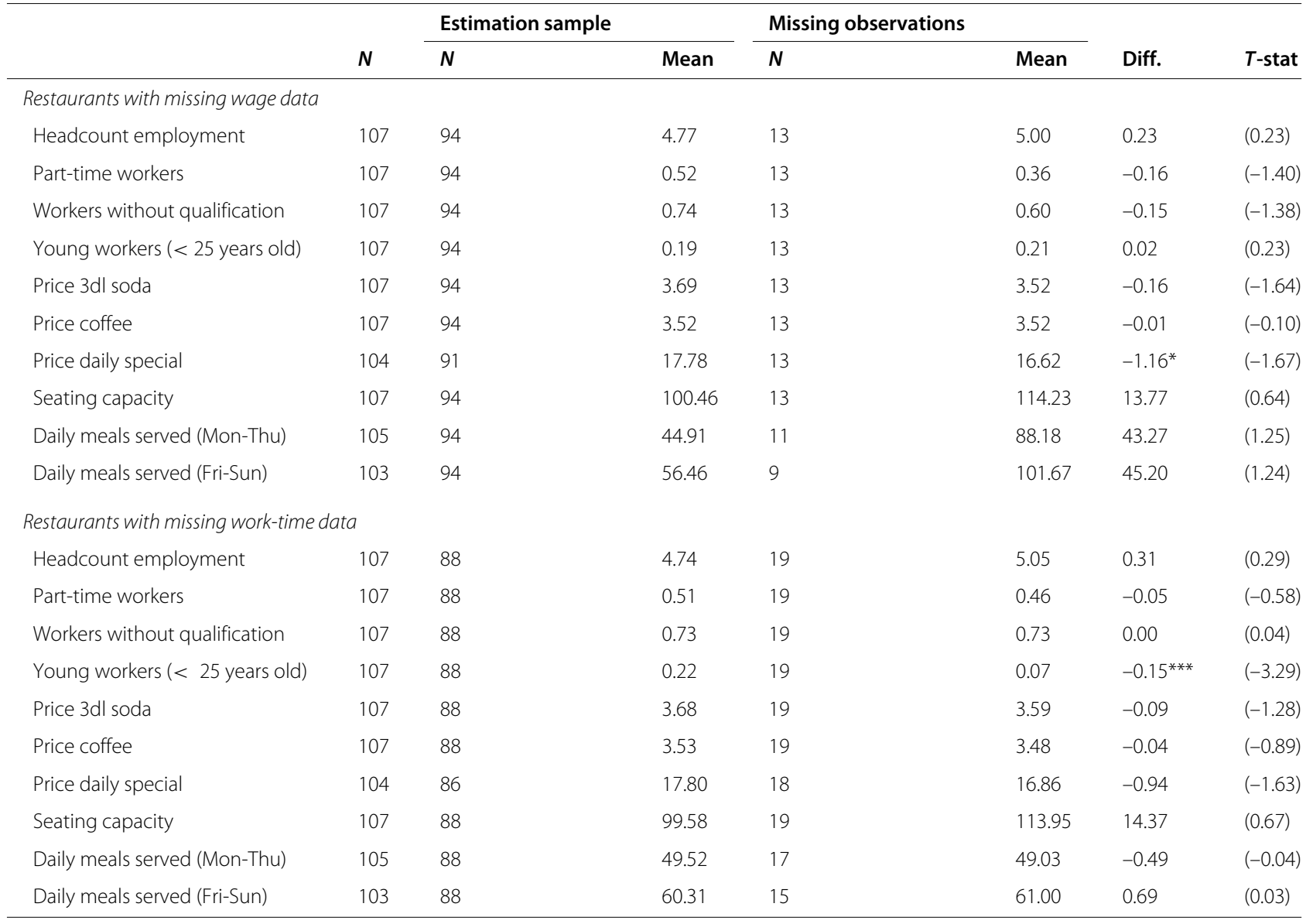

Notes: This table reports balance tests for restaurants with missing data for wages and work-time percentages, using pre-treatment data from the first wave of the survey. Excludes data for managers and members of their family. Workers without qualification are employees without a professional degree. Heteroskedasticity-robust t-statistics reported. $* * *$, and $* * *$ denote statistical significance at $10 \%, 5 \%$, and $1 \%$, respectively 


\section{Appendix B}

Table 10 Changes in employment for control and treatment groups by wage bin

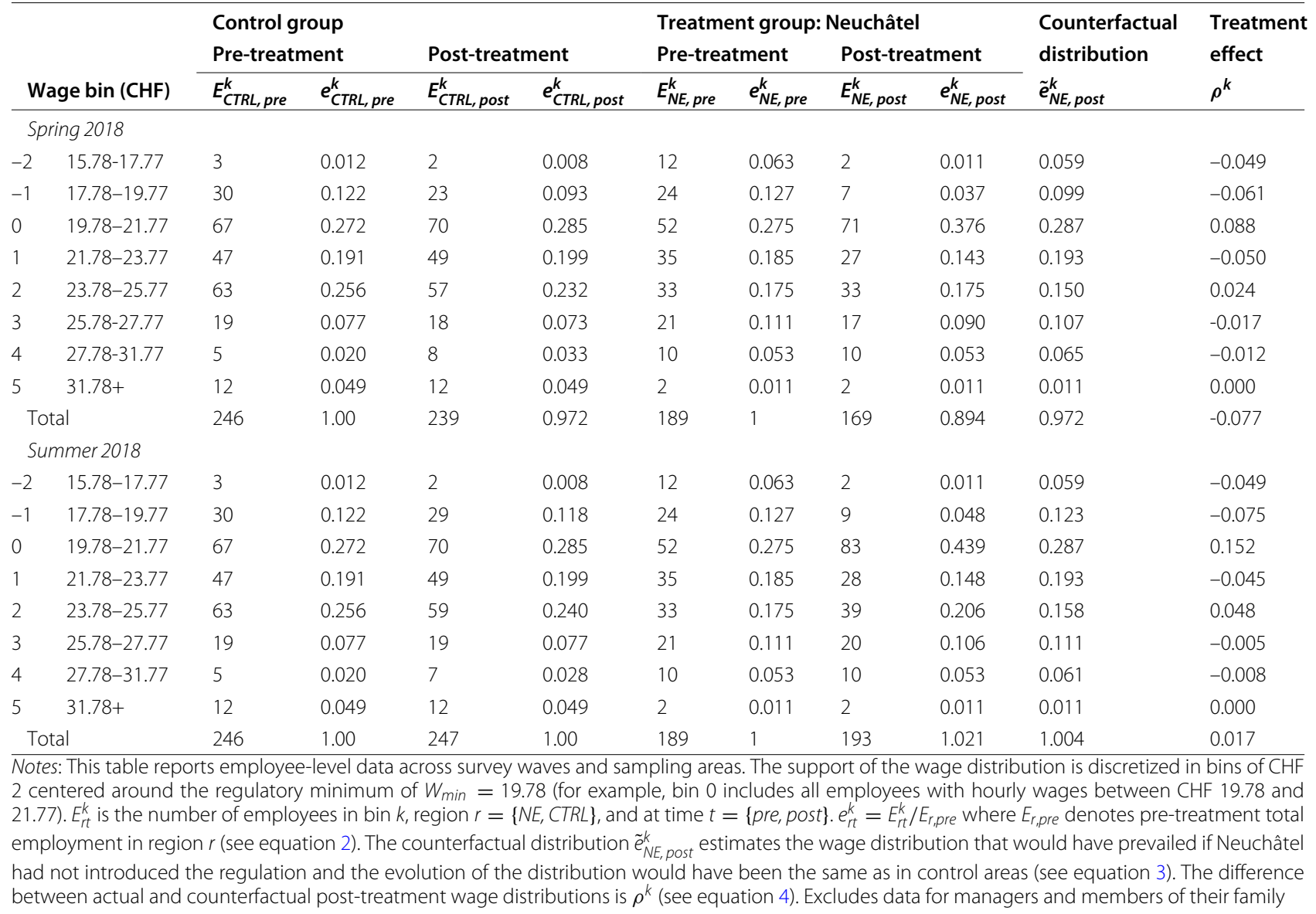




\section{Appendix C Restaurant-level impacts for linear specifications}

Table 11 Restaurant-level impacts on employment from OLS regressions (linear specifications)

\begin{tabular}{|c|c|c|c|c|}
\hline & Headco & & FTE & \\
\hline & (1) & (2) & (3) & (4) \\
\hline$D D_{\text {spring }}$ & -0.232 & -0.216 & -0.335 & -0.312 \\
\hline & $(0.290)$ & $(0.247)$ & $(0.218)$ & $(0.202)$ \\
\hline$D D_{\text {summer }}$ & 0.054 & 0.070 & -0.111 & -0.088 \\
\hline & $(0.255)$ & $(0.264)$ & $(0.201)$ & $(0.204)$ \\
\hline$\delta_{\text {spring }}$ & -0.095 & -0.055 & -0.166 & -0.190 \\
\hline & $(0.198)$ & $(0.181)$ & $(0.112)$ & $(0.118)$ \\
\hline$\delta_{\text {summer }}$ & 0.119 & 0.160 & -0.029 & -0.053 \\
\hline & $(0.208)$ & $(0.206)$ & $(0.142)$ & $(0.148)$ \\
\hline Controls & $N$ & Y & $N$ & Y \\
\hline$R^{2}$ & 0.050 & 0.072 & 0.079 & 0.084 \\
\hline$N$ restaurants & 94 & 94 & 88 & 88 \\
\hline
\end{tabular}

Notes: OLS regression coefficients reported. In columns (1) and (2), the outcome is headcount employment by restaurants. In columns (3) and (4), the outcome is FTE employment, which is based on reported work-time information for each employee and computed only for restaurants with complete working time data. All specifications include restaurant fixed effects and period fixed effects. Columns (2) and (4) include control variables "Daily meals served (Mon-Thu)" and "Daily meals served (Fri-Sun)." We exclude data for managers and members of their family from the estimation. Robust standard errors clustered at the restaurant level reported in parentheses. ${ }^{*}, *$, and $* * *$ denote statistical significance at $10 \%, 5 \%$, and $1 \%$, respectively 
Table 12 Restaurant-level impacts on prices from OLS regressions (linear specifications)

\begin{tabular}{|c|c|c|c|c|c|c|}
\hline & \multicolumn{2}{|c|}{ Price soda } & \multicolumn{2}{|c|}{ Price coffee } & \multicolumn{2}{|c|}{ Price daily special } \\
\hline & (1) & $(2)$ & (3) & (4) & (5) & (6) \\
\hline \multirow[t]{2}{*}{$\overline{D D_{\text {post }}}$} & -0.007 & 0.001 & 0.021 & 0.024 & 0.049 & 0.049 \\
\hline & $(0.033)$ & $(0.032)$ & $(0.030)$ & $(0.033)$ & $(0.101)$ & $(0.108)$ \\
\hline \multirow[t]{2}{*}{$\delta_{\text {post }}$} & 0.029 & 0.021 & -0.007 & -0.011 & 0.073 & 0.069 \\
\hline & $(0.018)$ & $(0.023)$ & $(0.027)$ & $(0.026)$ & $(0.069)$ & $(0.078)$ \\
\hline Controls & N & Y & N & Y & $N$ & Y \\
\hline$R^{2}$ & 0.022 & 0.055 & 0.007 & 0.013 & 0.044 & 0.046 \\
\hline$N$ restaurants & 94 & 94 & 94 & 94 & 91 & 91 \\
\hline
\end{tabular}

Notes: OLS regression coefficients reported. In columns (1) and (2), the outcome is the price of a $3 \mathrm{dl}$ soda. In columns (3) and (4), the outcome is the price of a coffee. In columns (5) and (6), the outcome is the price of the daily special. All specifications include restaurant fixed effects and columns (2), (4), and (6) include control variables "Daily meals served (Mon-Thu)" and "Daily meals served (Fri-Sun)." Robust standard errors clustered at the restaurant level reported in parentheses. *, **, and *** denote statistical significance at $10 \%, 5 \%$, and $1 \%$, respectively 


\section{Supplementary Information}

The online version contains supplementary material available at https://doi.org/10.1186/s41937-020-00067-5.

Additional file 1: Restaurant survey (2017-2018).

\section{Abbreviations}

CLA: Collective labor agreement; CTRL: Control; DD: Difference-in-differences; FTE: Full-time equivalent; NE: Neuchâtel

\section{Acknowledgements}

We would like to thank Michel Dubois, Peter Fiechter, Claude Jeanrenaud, Daniel Kaufmann, Marco Pecorraro, and Sylvain Weber for useful discussions and feedback, as well as David Card and Alan Krueger for sharing the questionnaire of their original study (Card and Krueger 1994). Excellent research assistance was provided by Nathan Delacrétaz. The opinions expressed in this article are the authors's own and do not reflect the view of their employers. The authors are responsible for any remaining errors.

\section{Authors' contributions}

Both authors contributed to the data collection, analysis, and writing of the paper. The authors read and approved the final manuscript.

\section{Funding}

We acknowledge the financial support from the University of Neuchâtel.

\section{Availability of data and materials}

The data used in this article are available from the corresponding author upon reasonable request and to other researchers only. This is to preserve the anonymity of participants in our survey, as some characteristics in the data could potentially be used to identify specific restaurants participating in our survey.

\section{Competing interests}

We have no competing interests to declare.

\section{Author details}

1 État de Neuchâtel, Neuchâtel, Switzerland. ${ }^{2}$ University of Neuchâtel, Neuchâtel, Switzerland. ${ }^{3}$ ETH Zürich, Zürich, Switzerland. ${ }^{4}$ Massachusetts Institute of Technology, Cambridge, USA.

\section{Received: 21 August 2019 Accepted: 20 October 2020}

Published online: 25 November 2020

\section{References}

Aaronson, D. (2001). Price pass-through and the minimum wage. The Review of Economics and Statistics, 83(1), 158-169.

AAronson, D., French, E., Sorkin, I., To, T. (2018). Industry dynamics and the minimum wage: a putty-clay approach. International Economic Review, 59(1), 51-84.

Addison, J., Blackburn, M., Cotti, C. (2009). Do minimum wages raise employment? Evidence from the U.S, retail-trade sector. Labour Economics, 16(4), 397-408

Ahlfeldt, G., Roth, D., Seidel, T. (2018). The regional effects of Germany's national minimum wage. Economics Letters, 172, 127-130.

Allegretto, S., Dube, A., Reich, M. (2011). Do minimum wages really reduce teen employment? Accounting for heterogeneity and selectivity in state panel data. Industrial Relations, 50(2), 205-240.

Allegretto, S., Dube, A., Reich, M., Zipperer, B. (2017). Credible research designs for minimum wage studies: a response to Neumark, Salas and Wascher. Industrial and Labor Relations Review, 70(3), 559-592.

Bysaeth, L. (2018). Le salaire minimum sera finalement de 19,70 francs de I'heure dans le canton de Neuchâtel (et non de 20). Arclnfo / L'impartial / L'Express, issue of the 31 August, Neuchâtel, Switzerland.

Card, D., \& Krueger, A.B. (1994). Minimum wages and employment: a case study of the fast-food industry in New Jersey and Pennsylvania. American Economic Review, 84(4), 772-793.
Card, D., \& Krueger, A. (2000). Minimum wages and employment: a case study of the fast food industry in New Jersey and Pennsylvania: Reply. American Economic Review, 90(5), 1397-1420.

Cengiz, D., Dube, A., Lindner, A., Zipperer, B. (2019). The effect of minimum wages on low-wage jobs: evidence from the United States using a bunching estimator. Quarterly Journal of Economics, 134(3), 1405-1454.

Council of State of Neuchâtel (2013). Salaire Minimum: rapport du Conseil d'Etat au Grand Conseil à l'appui d'un projet de loi portant modification de la loi sur l'emploi et l'assurance-chômage. Report 13.048, Cantonal Administration of the canton of Neuchâtel, Switzerland.

Della Pietra, N. (2018). Le Tessin s'achemine à son tour vers l'adoption d'un salaire minimal. Geneva: Radio Télévision Suisse.

Di Stefano, L. (2018). Vers un salaire minimum genevois? Switzerland: Tribune de Genève, Geneva.

Doyle, J. (2005). Employment effects of a minimum wage: a density discontinuity design revisited. MIT Sloan School working paper.

Dube, A., Lester, T.W., Reich, M. (2010). Minimum wage effects across state borders: estimates using contiguous counties. The Review of Economics and Statistics, 92(4), 945-964.

Dube, A., Naidu, S., Reich, M. (2007). The economic effects of a citywide minimum wage. Industrial and Labor Relations Review, 60(4), 522-543.

Federal Court (2017). Arrêt du Tribunal Fédéral du 21 Juillet 2017: Federal Supreme Court of Switzerland.

Federal Statistical Office (2017). Statistique structurelle des entreprises. Neuchâtel, Switzerland.

GastroNeuchâtel (2018). Sondage 2017, Commentaires et communiqué de presse. St-Blaise: Chambre cantonale de l'hôtellerie et de la restauration.

GastroSuisse (2018). Reflet économique de la branche 2018. Zürich, Switzerland: Fédération de l'hôtelerie et de la restauration.

Giroud, V. (2018). Salaire minimum encore trangressé. Arclnfo / L'impartial / L'Express, issue of the 3 November, Neuchâtel, Switzerland.

Giuliano, L. (2013). Minimum wage effects on employment, substitution, and the teenage labor supply: Evidence from personnel data. Journal of Labor Economics, 31(1), 155-194.

Giupponi, G., \& Machin, S. (2018). Changing the structure of minimum wages: firm adjustment and wage spillovers. Institute for the Study of Labour Discussion Paper.

Harasztosi, P., \& Lindner, A. (2019). Who pays for the minimum wage? American Economic Review, 109(8), 2693-2727.

Jardim, E., Long, M.C., Plotnick, R., van Inwegen, E., Vigdor, J., Wething, H. (2017). Minimum wage increases, wages, and low-wage employment: evidence from Seattle. NBER Working Paper.

Kontrollstelle L-GAV (2017). Der Gesamtarbeitsvertrag im Schweizer Gastgewerbe. Basel, Switzerland: Kontrollstelle für den L-GAV des Gastgewerbes.

Lang, K., \& Kahn, S. (1998). The effect of minimum-wage laws on the distribution of employment: theory and evidence. Journal of Public Economics, 69(1), 67-82.

Lee, D., \& Saez, E. (2012). Optimal minimum wage policy in competitive labor markets. Journal of Public Economics, 96(9-10), 739-749.

Lemos, S. (2008). A survey of the effects of the minimum wage on prices. Journal of Economic Surveys, 22(1), 187-212.

Leonard, M.L., Stanley, T., Doucouliagos, C. (2014). Does the UK minimum wage reduce employment? A meta-regression analysis. British Journal of Industrial Relations, 52(3), 499-520.

Machin, S., Manning, A., Rahman, L. (2003). Where the minimum wage bites hard: introduction of minimum wages to a low wage sector. Journal of the European Economic Association, 1(1), 154-180.

Metcalf, D. (2008). Why has the British national minimum wage had little or no impact on employment? Journal of Industrial Relations, 50(3), 489-512. https://doi.org/10.1177/0022185608090003.

Neumark, D., Salas, J.M.I., Wascher, W. (2014). Revisiting the minimum wage-employment debate: throwing out the baby with the bathwater? Industrial and Labor Relations Review, 67, 608-648.

Neumark, D., Schweitzer, M., Wascher, W. (2004). Minimum wage effects throughout the wage distribution. Journal of Human Resources, 39(2), 425-450.

Neumark, D., \& Wascher, W. (2000). Minimum wages and employment: a case study of the fast-food industry in New Jersey and Pennsylvania: Comment. American Economic Review, 90(5), 1362-1396.

Neumark, D., \& Wascher, W. (2008). Minimum Wages. Cambridge MA, USA: The MIT Press. 
Neumark, D., \& Wascher, W. (2017). Reply to Credible research designs for minimum wage studies. Industrial and Labor Relations Review, 70(3), 593-609.

Renkin, T., Montialoux, C., Siegenthaler, M. (2017). The pass-through of minimum wages into U.S. retail prices: evidence from supermarket scanner data. Working paper.

SECO (2018). Labor market statistics. Bern: Swiss State Secretariat for Economic Affairs.

\section{Publisher's Note}

Springer Nature remains neutral with regard to jurisdictional claims in published maps and institutional affiliations.

\section{Submit your manuscript to a SpringerOpen ${ }^{\circ}$} journal and benefit from:

- Convenient online submission

- Rigorous peer review

- Open access: articles freely available online

- High visibility within the field

- Retaining the copyright to your article

Submit your next manuscript at $\boldsymbol{\wedge}$ springeropen.com 